This is the last draft sent to the Editorial by the authors of the article:

M. GÓMEZ, P. VALLES, S. F. MEDINA

"Evolution of Microstructure and Precipitation State during Thermomechanical Processing of a X80 Microalloyed Steel"

Materials Science and Engineering A

Vol. 528 (2011), Pages: 4761-4773

DOI: 10.1016/j.msea.2011.02.087

ISSN: 0921-5093

To be published in Digital.CSIC, the Institutional Repository of the Spanish National Research Council (CSIC)

See more papers from the authors on:

http://digital.csic.es

http://www.researcherid.com/rid/B-7922-2008 


\title{
EVOLUTION OF MICROSTRUCTURE AND PRECIPITATION STATE DURING THERMOMECHANICAL PROCESSING OF A X80 MICROALLOYED STEEL
}

\author{
Manuel GOMEZ ${ }^{\mathrm{a}^{*}}$, Pilar VALLES ${ }^{\mathrm{b}}$, Sebastián F. MEDINA ${ }^{\mathrm{a}}$ \\ a National Center for Metallurgical Research (CENIM-CSIC), Avda. Gregorio del Amo 8, 28040 Madrid, Spain, \\ mgomez@cenim.csic.es, smedina@cenim.csic.es \\ ${ }^{\mathrm{b}}$ Instituto Nacional de Técnica Aeroespacial (INTA), Ctra. Torrejón-Ajalvir, Km.4. 28850 Torrejón de Ardoz, Madrid, \\ Spain, vallesgp@inta.es
}

* Corresponding author: Tel. +34 915538900; fax: +34 915347425.

\begin{abstract}
A series of anisothermal hot torsion tests were carried out to simulate hot rolling on a high-strength low-carbon CMnNbMoTi microalloyed steel corresponding to an industrial X80 grade for pipeline construction. Mean Flow Stress was graphically represented against the inverse of temperature to characterize the evolution of austenite microstructure during rolling, which was also studied by optical microscopy and SEM on samples quenched from several temperatures. On the other hand, particles precipitated at different temperatures during rolling were analyzed by means of TEM using the carbon extraction replica technique and their size distribution and mean size were determined, as well as their morphology, nature and chemical composition. The effect of rolling temperature and austenite strengthening obtained at the end of thermomechanical processing on final microstructure and precipitation state was studied. Austenite strengthening was characterized by means of the parameter known as accumulated stress $(\Delta \sigma)$. It was found that ferrite grains are finer and more equiaxed when the austenite is more severely deformed during finishing (higher values of $\Delta \sigma$ ) but lower values of $\Delta \sigma$ generate a higher density of acicular structures after cooling, which should improve the balance of mechanical properties. The increase in strength associated to acicular ferrite compared to polygonal ferrite is revealed by the higher values of Vickers microhardness measured on samples corresponding to low $\Delta \sigma$. On the other hand, (Ti, $\mathrm{Nb}$ )-rich carbonitrides can be found from reheating and their size keeps a constant value near 20-30 nm during thermomechanical processing. A second population of much finer (Nb, Mo)-rich carbonitrides whose size is close to 5 $\mathrm{nm}$ forms from lower temperatures, near $1000^{\circ} \mathrm{C}$. The accomplishment of two different levels of $\Delta \sigma$ at the end of hot rolling schedule does not seem to introduce major differences in precipitation state before final cooling.
\end{abstract}

KEYWORDS: Transmission electron microscopy; Microalloyed steel; Pipeline; Thermomechanical processing; Acicular ferrite; Precipitation.

\section{INTRODUCTION}

The demand of sources of energy such as oil and natural gas grows steadily. These natural resources are often located in regions far from the market or with extremely low temperatures, there being a need of higher operating pressures to increase the capacity of pipelines. As a result, steels with higher strength, higher toughness and good formability are currently in high demand in order to get a reliable and safer access to energy. Furthermore, the utilization of stronger steels for the construction of pipelines involves significant reductions of wall thickness, weight and volume that lead to significant savings in multiple areas such as transportation, welding or coating. Consequently, cost reductions of up to $15 \%$ can be achieved in long distance pipeline projects [1-3].

The steel industry is developing ultrahigh strength low carbon microalloyed pipeline steels whose microstructure provides an outstanding combination of properties. These steels include a strict combination of alloying and microalloying elements to obtain good weldability, adequate strength in corrosive environment and a precise balance of microconstituents in order to achieve excellent mechanical properties at a reduced cost [4-7]. To obtain an adequate fine-grained final microstructure, the strict control of thermomechanical processing (reheating temperature, percentage reduction, interpass times, roughing and finishing temperatures) and accelerated cooling (delay time between finish rolling and the onset of accelerated cooling, cooling start temperature, cooling rate, cooling stop temperature) is also crucial for the strength and toughness properties [8-12].

Depending on the thermomechanical processing conditions and chemical composition, pipeline steels can present different combinations of microstructures $[6,13,14]$. Several authors have found that the microstructure of acicular ferrite usually provides an optimum combination of mechanical properties [6, 15-20]. Compared to a microstructure of polygonal ferrite, acicular ferrite contains higher density of dislocations and sub-boundaries, which is beneficial to the strength. At the same time, cleavages in an acicular ferrite pipeline steel experience more bent paths and absorb more energy at low temperatures [6]. Acicular ferrite is often composed of interwoven nonparallel ferrite laths with high 
dislocation density, dispersed precipitation of carbonitrides and ultrafine islands of carbon-enriched martensite/austenite (M/A) inside or among the laths [8, 18]. The formation mechanism of acicular ferrite provides a refinement of the mixed microstructure [21-23] that is known to be beneficial for the balance of mechanical properties of strength and toughness. Another important feature of the microstructure of acicular ferrite is the continuous yielding and rapid work hardening during the fabrication of plate into pipe [16]. The environment for acicular ferrite formation in hot rolled pipeline steels is quite different from that of welds, as nonmetallic inclusions acting as nucleation sites inside the austenite grains are extremely restricted in pipeline steels. Acicular ferrite forms through a mixed diffusion and shear mechanism during continuous cooling subsequent to hot rolling. It forms at a temperature range slightly above bainite [15] and mainly nucleates on dislocations and other defects within the grain [8, 20]. In pipeline steels, an increase in the amount of hot-deformation in the austenite non-recrystallization region during thermomechanical processing increases the volume fraction of acicular ferrite after cooling at the expense of bainitic ferrite. This results from the higher density of substructure and dislocations within the austenite grains, which increases the nucleation rate of acicular ferrite $[8,10$, $18,20,24-27]$. This also impedes the growth of $\gamma / \alpha$ interfaces and accelerates the diffusion of carbon to the $\gamma / \alpha$ interface, which can give rise to carbon-enriched austenite due to the partitioning of carbon [20]. On the other hand, it is known that the refinement of ferritic microstructure is enhanced by a fine-grained austenite before transformation, and especially by a microstructure of strengthened austenite with elongated grains, high dislocation density and ledges in the grain boundaries that increase the density of nucleation sites and promote high nucleation rates for ferrite [9, 28, 29]. The total degree of roughing and especially the final deformation degree have a great influence on the toughness and strength properties, more than the deformation degree of the single passes. In relation to this matter, this work studies the effect of austenite strengthening during and at the end of thermomechanical processing on phase transformation and final microstructure after cooling. Metallographic observations are combined with the measurement of the parameter known as accumulated stress $(\Delta \sigma)$ to characterize progressive strengthening of austenite during rolling at temperatures below no-recrystallization temperature $\left(\mathrm{T}_{\mathrm{nr}}\right)$ and to study the grain size and balance of phases of final microstructure.

On the other hand, the evolution of precipitation state during hot rolling is also described in this paper. The straininduced precipitates formed by microalloying elements and interstitials play a very important role on the microstructure evolution and final mechanical properties of conventional microalloyed steels with a microstructure of ferrite-pearlite [30,31]. Some authors have studied the precipitation state in low-carbon pipeline steels with a microstructure of acicular ferrite or bainite [13, 19, 23, 32, 33]. However, these works have mainly focused on the precipitation state of final product and the evolution of precipitation during thermomechanical processing of austenite has not been extensively studied in these steels. This work makes use of hot rolling simulations interrupted by quenching tests to characterize the precipitation state at different stages of thermomechanical processing of a low-carbon microalloyed steel designed for pipeline applications. In particular, the precipitation of Mo-containing particles in austenite is studied in this work. Mo is very soluble in austenite and causes a solute drag effect on static [34,35] and dynamic [36] recrystallization of austenite that is stronger than that of $\mathrm{V}$ but normally weaker than that of $\mathrm{Nb}$ in solution. The addition of Mo to low carbon Nb microalloyed steels causes an additional solute drag effect that helps to increase the value of $T_{\mathrm{nr}}$ temperature, although this effect is weaker for increasing $\mathrm{Nb}$ additions [37, 38]. On the other hand, Mo in solution is known to delay the precipitation of $\mathrm{NbCN}$ in Nb-Mo microalloyed steels [36, 39]. Consequently, the precipitation of fine Nb-Mo precipitates in the ferrite that are beneficial for strengthening is easier [16] and accordingly the importance of final cooling and coiling temperatures to enhance precipitation strengthening has been suggested [8]. In fact, it is usually assumed that fine Mo carbides or carbonitrides do not form in austenite and only precipitate during transformation or already in the ferrite phase [36, 40,41]. The absence of Mo precipitates in austenite might be true for pure Mo carbonitrides formed with single Mo additions [42], but it has been observed that Ti and Nb carbonitrides or carbides precipitated in the austenite are significantly complex in nature and can also include a certain amount of Mo [39, 43-46]. This work makes an effort to characterize the complex Mo-containing particles formed in austenite. Finally, the effect of austenite strengthening at the end of hot rolling on strain-induced precipitation state is also assessed.

\section{EXPERIMENTAL PROCEDURE}

The steel studied was an industrial API 5L X80 type for pipeline applications. As Table 1 shows, this steel is a lowcarbon, high-Mn (Nb, Ti)-microalloyed steel with increased hardenability obtained thanks to Mo, $\mathrm{Ni}$ and $\mathrm{Cu}$ additions. $\mathrm{Ni}$ and $\mathrm{Cu}$ can restrain the formation of acicular ferrite [20], but Mo can enhance the formation of this constituent as well as bainite and M-A [5] and reduce pearlite formation [26]. On the other hand, Nb is known to be the microalloying element that most delays static recrystallization kinetics, even when it is in solution [47] and Ti additions help to control austenite grain growth at high temperatures but exert a moderate effect on recrystallization inhibition [48].

A series of rolling simulation tests were carried out in a computer-controlled hot torsion machine, on specimens with a gauge length of $50 \mathrm{~mm}$ and a diameter of $6 \mathrm{~mm}$ that were protected against oxidization with an argon flow. Simplified multipass hot-torsion schedules are frequently used to determine hot rolling critical temperatures (no-recrystallization temperature $T_{\mathrm{nr}}$ and phase transformation temperatures $\mathrm{A}_{\mathrm{r} 3}$ and $\mathrm{A}_{\mathrm{r} 1}$ ). In this kind of simulation schedules, average values of rolling conditions (such as pass strain, interpass time or temperature step between passes) are kept constant 
throughout the test [28, 49, 50]. On the other hand, 'closer-to-real' schedules can also be designed with the aim of better simulating a specific industrial hot rolling process [49-51]. This is the case of present work, where a complex schedule was employed, albeit it was necessary to introduce some simplifications (for example in the number of passes) due to practical limitations of the hot torsion machine.

Prior to the simulation tests, the specimens were austenitized at a temperature of $1150^{\circ} \mathrm{C}$ for $15 \mathrm{~min}$. The theoretical solubility temperatures calculated for carbonitrides, nitrides and carbides [52] are shown in Table 2. According to these values, a certain fraction of undissolved TiN particles will remain after reheating. Besides, the presence of undissolved $\mathrm{Nb}$ carbonitrides can be expected, as the solubility temperature for these precipitates is close to the reheating temperature. The temperature was then lowered to that corresponding to the first deformation pass, which was $1125^{\circ} \mathrm{C}$. The simulations consisted of the performance of 16 or 17 passes following the schedules shown in Table 3 . The schedule was divided in three phases and it was designed to achieve full recrystallization in Phase 1 at high temperatures and austenite strengthening by partial or no recrystallization during Phases 2 and 3. Phases 1 and 2 were common to all tests. A long time interval with a strong temperature step between Phases 1 and 2 ensured that last finishing passes are applied within the pancaking domain. To study the influence of austenite strengthening on several aspects (microstructure, precipitation state) the strain applied during Phase 3 (i.e. at lower temperatures close to phase transformation) took three different values. Doing so, three different levels of austenite strengthening at the end of hot rolling were attained and consequently the magnitude known as accumulated stress $(\Delta \sigma)[28,53]$ achieved three different values.

Dilatometric tests were carried out in order to determine the $\mathrm{A}_{\mathrm{r} 3}$ temperature and to verify if hot rolling finished at a temperature where microstructure was still fully austenitic. In order to characterize the evolution of austenite microstructure and precipitation state during hot rolling, several samples were water-quenched from different temperatures along the hot rolling simulation schedules, under the conditions shown in Table 4. In some cases, the samples were quenched just after deformation and in other cases a deformation step was performed and the temperature was then lowered for the corresponding interpass time to reach the quenching temperature and to characterize the microstructure before next deformation. The effect of austenite strengthening (value of $\Delta \sigma$ ) on final microstructure and precipitation was assessed in samples quenched from $750^{\circ} \mathrm{C}$ and with different levels of accumulated stress. To study final microstructures, two other samples were cooled in argon from $750^{\circ} \mathrm{C}$ after applying the corresponding deformation in Phase 3.

The samples were prepared by metallographic techniques and microstructures were observed by optical microscopy and scanning electron microscopy (SEM) on a longitudinal surface of the specimens at $2.65 \mathrm{~mm}$ from the axis. The primitive austenite grain boundaries were revealed by etching the quenched samples with an aqueous solution of saturated picric acid mixed with a wetting agent. The final microstructures obtained after cooling were observed after etching with $2 \%$ nital. Partial etching of grain boundaries always causes uncertainties in the quantification of phases in complex microstructures of acicular/polygonal ferrite, but this standard etchant has been found as the most appropriate to study these microstructures by optical microscopy [26]. Vickers Microhardness values were measured on the samples quenched or cooled from $750{ }^{\circ} \mathrm{C}$ according to UNE-EN ISO 6507-1 standard using a load of 5 kgf. The characteristics of the precipitates were determined by transmission electron microscopy (TEM), using the carbon extraction replica technique. The replicas were taken at the same depth of $2.65 \mathrm{~mm}$ from the axis. In each replica a population of no less than 400 particles was counted and their size was measured with the aim of calculating the mean size. Energy dispersive $\mathrm{X}$-ray (EDX) analysis was carried out to characterize the chemical composition of the particles observed.

\section{RESULTS}

The torsion test gives the values of torque applied versus the number of turns made on the specimen, which are transformed respectively into equivalent stress and strain using Von Mises criterion [54]. The microstructural evolution of steel during hot rolling is usually studied on the curves of Mean Flow Stress (MFS) versus the inverse of temperature. MFS is determined in each step by dividing the area below the stress-strain curve by the strain applied [49]. Figure 1 shows an example of a MFS plot for a conventional hot rolling simulation on the steel studied, where average values of strain, strain rate and interpass time have been used throughout the test. In this figure it is possible to see three different zones. In the first zone (I), which corresponds to deformations at high temperatures, MFS grows as temperature decreases. Austenite recrystallizes completely between passes and the increase in stress is due only to the decrease in temperature. In the second zone of the curve (phase II) there is a change in the slope, which indicates a greater tendency towards hardening. Here the stress accumulates in the austenite, whose recrystallization between passes is partially inhibited by the strong pinning effect of strain-induced precipitates of microalloying elements. At lower temperatures (phase III) the value of MFS suffers a temporary and slight decrease because austenite transforms to ferrite, which is a softer phase. The intersection of the straight regression lines of phases I and II defines the value of $\mathrm{T}_{\mathrm{nr}}$ and the intersection of the regression lines of phases II and III determines the value of $A_{\mathrm{r} 3}$ [49]. The apparent eutectoid transformation temperature $\left(\mathrm{A}_{\mathrm{r} 1}\right)$ [55] can be approximated to the minimum of the parabola corresponding to phases III and IV [28]. The increase of stress at lower temperatures (phase IV) indicates the cooling of ferrite-pearlite 
microstructure. The magnitude known as "accumulated stress" $(\Delta \sigma)$ will be given by the length of the vertical segment drawn between the straight regression lines of phases I and II, as illustrated in Fig. 1 . The value of $\Delta \sigma$ informs about the progressive strengthening of austenite during rolling at temperatures below $\mathrm{T}_{\mathrm{nr}}$. $\Delta \sigma$ is zero a $\mathrm{T}=\mathrm{T}_{\mathrm{nr}}$ and grows during phase II to reach its maximum value at $\mathrm{A}_{\mathrm{r} 3}$ [53].

Figure 2 shows the MFS plot for the industrial hot rolling simulation schedule. Phase 1 corresponds here to roughing deformations at high temperatures. After an interphase cooling interval of $410 \mathrm{~s}$, the second zone of the curve (Phase 2 ) shows higher values of stress due to the higher values of pass strain applied. Besides, an increase in the slope can be observed, which denotes the accumulated stress due to the incomplete recrystallization of austenite between finishing passes. In Phase 3, the rolling schedule has been modified to obtain different levels of strengthening (three values of $\Delta \sigma$ ). Compared to the tendency observed in the points of Phase 2, a drop in the value of MFS can be observed in Phase 3. This can be easily understood for low and medium values of $\Delta \sigma$ because the strain applied in the last pass of both tests is lower than 0.3 (see Phases 3a and $3 \mathrm{~b}$ in Table 3), so the value of MFS is logically lower. However, the test corresponding to the highest $\Delta \sigma$, where the strain applied at $760{ }^{\circ} \mathrm{C}$ is exactly the same as in previous passes (0.3), also shows a certain decline in the slope of MFS plot during Phase 3c. As can be seen in Table 3, the last deformation is always applied at $750{ }^{\circ} \mathrm{C}$ and this temperature is reached at a cooling rate of 1 or $2{ }^{\circ} \mathrm{C} / \mathrm{s}$. Dilatometric curve of Figure 3 shows that $\mathrm{A}_{\mathrm{r} 3}$ phase transformation temperature at $1{ }^{\circ} \mathrm{C} / \mathrm{s}$ is close to $700{ }^{\circ} \mathrm{C}$. According to this, hot deformations should be always applied to a fully austenitic microstructure, i.e. the decrease in MFS in the last passes for the referred cases would not be caused by the start of ferrite formation. The empirical equation of Ouchi et al. [56] predicts an $A_{r 3}$ value for this steel after controlled hot rolling of $707^{\circ} \mathrm{C}$. However, Figure 1 shows that $\mathrm{A}_{\mathrm{r} 3}$ temperature measured under hot deformation conditions can be much closer to $750^{\circ} \mathrm{C}\left(738^{\circ} \mathrm{C}\right)$ due to the high density of potential nucleation sites for ferrite [57]. Consequently, a certain degree of intercritical deformation might be expected, i.e. a small fraction of ferrite could have formed before last deformations are applied at $760^{\circ}-750^{\circ} \mathrm{C}$. In contrast, and more importantly, a certain fraction of softening due to static restoration during the relatively long interphase time of $60 \mathrm{~s}$ between $810^{\circ} \mathrm{C}$ and the last pass of industrial rolling might happen [50]. Static recovery helps to reduce available sites for ferrite nucleation so a limited increase of $\mathrm{A}_{\mathrm{r} 3}$ due to deformation can be expected [58]. In sum, the decrease in MFS value observed (or in the slope of MFS plot) would correspond mostly to restoration of austenite during the cooling interval between phases 2 and 3.

Figure 4 shows the evolution of austenite microstructure during hot rolling simulation shown in Figure 2. The initial grain size after reheating is fine, below $20 \mu \mathrm{m}$ (Fig. 4a), due to the grain growth control exerted by Ti precipitates. The microstructure just after deformation at $1105^{\circ} \mathrm{C}$ (i.e. after 5 rolling passes) presents a number of slightly elongated grains (Fig. 4b), but the interpass time of $10 \mathrm{~s}$ is long enough to allow a fully recrystallized microstructure when the temperature of next pass $\left(1100^{\circ} \mathrm{C}\right)$ is reached (Fig. 4c). Besides, the fine size of austenite grain will contribute to accelerate recrystallization kinetics [35]. A similar behavior is observed between $1075{ }^{\circ} \mathrm{C}$ (Fig. $\left.4 \mathbf{d}\right)$ and $870{ }^{\circ} \mathrm{C}($ Fig. 4e). In the latter case, the long cooling interval of $410 \mathrm{~s}$ between phases 1 and 2 has even allowed a slight growth of recrystallized grain size, despite the presence of microalloying precipitates that are expected to control grain growth. The chance of grain coarsening during the interphase time after roughing in similar Ti/Mo-alloyed steels has been recently suggested elsewhere [50]. At the end of phase $2\left(810^{\circ} \mathrm{C}\right.$, Fig. $\left.\mathbf{4 f}\right)$ the austenite microstructure consists of strongly elongated grains with a high dislocation density. This microstructure, together with the relatively short distance to phase transformation temperature $\mathrm{A}_{\mathrm{r} 3}$, makes it more difficult to distinguish the austenite grain boundaries by etching of the quenched microstructures. This can be also noticed in Fig. $\mathbf{4 g}$, taken at $760{ }^{\circ} \mathrm{C}$, i.e. in Phase 3 . The immediacy of $\mathrm{A}_{\mathrm{r} 3}$ temperature and the strengthening of austenite make it possible to obtain a certain amount ferrite grains that formed during last deformation [24] or during quenching. Besides, the water from automatic quenching system always takes a very short time to completely dip the sample so some degree of ferrite formation during quenching or cooling after deformation can happen, especially in the heavily deformed samples that contain a higher density of potential nucleation sites. On the other hand, the aforementioned restoration during the interphase time of $60 \mathrm{~s}$ between $810{ }^{\circ} \mathrm{C}$ and $760{ }^{\circ} \mathrm{C}$ might have also happened.

Figure 5 shows the microstructure of samples quenched from $750{ }^{\circ} \mathrm{C}$ (i.e. at the end of hot rolling schedule) and etched to reveal austenite grain boundaries. The effect of the strain applied in the last pass on grain elongation can be observed in the samples corresponding to low and medium values of $\Delta \sigma$ (Figs. 5a and $\mathbf{5 b}$ ). Fig. 5c shows that the sample suffering stronger deformations at low temperatures (high value of $\Delta \sigma$ ) presented elongated austenite grains but also a remarkable fraction of very fine equiaxed grains that might be ferrite grains formed during last deformation or during the onset of quenching. As above mentioned, the real value of $\mathrm{A}_{\mathrm{r} 3}$ during rolling can be close to $750{ }^{\circ} \mathrm{C}$ and there can be some level of ferrite formation during the start of accelerated cooling. Figure 6 shows the microstructure of nital-etched samples corresponding to low and high values of $\Delta \sigma$. The austenite that was less severely deformed at $750{ }^{\circ} \mathrm{C}$ (Phase $3 \mathrm{a}$ in Table 3) gives rise to a microstructure after quenching where acicular ferrite is easily observed. However, higher values of $\Delta \sigma$ (Phase 3c) obtained by applying two consecutive pass strains of 0.3 at $760{ }^{\circ} \mathrm{C}$ and $750{ }^{\circ} \mathrm{C}$ lead to a very fine distribution of more equiaxed ferrite grains. Several authors have previously found that samples that suffered hot deformation can present acicular ferrite microstructures after very rapid cooling $[8,24]$ and acicular ferrite can be formed in X70-80 steels even at cooling rates near $75^{\circ} \mathrm{C} / \mathrm{s}$ [20]. If prior austenite grain size is very fine, as is the case of 
present study, hardenability is lowered and quasi-polygonal or polygonal ferrite can also be found after deformation followed by fast cooling [10].

Figure 7 shows the microstructure of two other nital-etched samples that went through the same schedules 3a and 3c but were slowly cooled in an argon flow from $750^{\circ} \mathrm{C}$. The cooling rate during transformation was near $3.5^{\circ} \mathrm{C} / \mathrm{s}$, which is similar to the reported cooling rate for the core of a heavy plate [12]. The effect of austenite strengthening at the end of hot rolling is observed again: ferrite grains are finer and more equiaxed when austenite is more heavily deformed (higher values of $\Delta \sigma$ ), which agrees with previous results that proved the remarkable refinement of final microstructure by hot deformation of austenite [9, 28, 29]. On the other hand, lower values of $\Delta \sigma$ generate more acicular structures after cooling. Several authors have observed that the higher density of substructure and dislocations in deformed austenite displace the transformation products from bainitic microstructures to acicular ferrite firstly [18, 20] or even to polygonal ferrite and pearlite for slower cooling rates or low hardenabilities [8, 10, 16, 24, 25, 27, 57-59]. It has been reported that prior deformation of the austenite below $\mathrm{T}_{\mathrm{nr}}$ and before final cooling could enhance acicular ferrite formation (at the expense of bainite) even more than the addition of molybdenum [26]. This enhancement of high temperature phases by deformation of the austenite below $T_{\mathrm{nr}}$ is more noticeable in boron-added steels [27]. In microalloyed steels with low hardenability (for example with ultralow carbon content) recrystallization controlled rolling routes (with finishing temperatures above Tnr) followed by accelerated cooling can be an interesting processing alternative [27]. These schedules have high productivity, lower mill loading than controlled rolling and let to achieve a high strength derived from a greater precipitation strengthening [60] and also from the formation of harder phases, although impact toughness can deteriorate [27].

Figure 8 shows the values of Vickers microhardness (HV) measured on six samples that were quenched or slowly cooled from $750^{\circ} \mathrm{C}$ after following hot rolling simulation schedules that led to three different levels of austenite strengthening. $\mathrm{HV}$ is represented in this figure as a function of accumulated stress $\Delta \sigma$ measured at the end of hot rolling, taking the lowest $\Delta \sigma$ as 0 . Measured values of HV are comprised between 216 for a severely deformed, slowly cooled sample and 258 for a quenched sample with low $\Delta \sigma$. Hardness values of 180-200 HV for quasi-polygonal ferrite and 240-290 HV for acicular ferrite have been reported for a similar steel with higher hardenability [58]. Similarly, hot deformed steels with $0.03 \% \mathrm{C}$ present hardness values between $170 \mathrm{HV}$ and $270 \mathrm{HV}$ depending on the preponderant phase in the mixed microstructure, from polygonal ferrite to bainitic ferrite [27]. Quenched samples obviously present higher values of $\mathrm{HV}$ than cooled samples and the interval of $\mathrm{HV}$ values shown in Fig. 8 could be well considered as the range of hardness values that can be achieved for intermediate cooling rates. As can be seen in the figure, the hardness of the samples decreases for increasing values of $\Delta \sigma$ and this happens with a similar trend for both cooling rates. Figs. 6 and 7 showed that ferrite grain size refinement is enhanced when the austenite is more severely deformed. It is wellknown that a finer ferritic microstructure helps to improve the balance of mechanical properties. However, the higher fraction of acicular ferrite obtained for lower values of $\Delta \sigma$ gives rise to higher values of strength. Manohar et al [57] also found that the hardness of low carbon steels can decrease after more severe deformations below Tnr, as the latter brings about a simultaneous refinement of ferrite grain size and a decrease in the hardenability of deformed austenite. Thermo-mechanically processed steels show a wider transformation temperature range than undeformed steels, so an optimized cooling schedule might retain the very fine microstructure advantageous for toughness together with higher strength multiphase microstructures [57]. Acicular ferrite possesses higher yield strength than ultrafine ferrite due to its dispersed precipitations of carbonitrides, higher density of dislocations and sub-boundaries and finer cleavage facet size $[6,19]$. The relationship between hardness and strength depends on the type of material and its processing and the conversion of hardness values to strength should always be taken as an approximation [61]. According to the results from several authors [62-67], a simplified linear relationship between Vickers Hardness number (HV) and yield strength $\left(\sigma_{y}\right)$ in MPa for a low carbon pipeline steel could be:

$\sigma_{y}=C \cdot H V$

where $\mathrm{C}$ is a constant in the region of 2.5-2.9 that depends on strain hardening exponent [62]. As seen in Fig. 8, estimated values of yield strength for cooled samples (considering $C=2.6$ ) would be close to the specified minimum yield strength (SMYS) of 551 MPa for an X80 grade [11, 68]. The values of yield strength estimated for quenched samples would be at least $640 \mathrm{MPa}$, near the lower limit for an X90 grade. An increase of $30 \mathrm{MPa}$ in yield strength is obtained for the sample with lower $\Delta \sigma$ and more acicular ferrite.

A linear relationship like Eq. (1) can also be used to estimate ultimate tensile strength (UTS) values in MPa from HV $[62,64]$. For low carbon pipeline steels, the best agreement is now obtained for a value of C near 3.2 [61, 65, 66], i.e.:

$U T S=3.2 \cdot H V$

This represents an estimated UTS range around 690-825 MPa for the samples studied. The value of UTS of an API X80 grade steel must be above $620 \mathrm{MPa}$ or between 690-840 MPa according to analogous DIN 17172 standard [68]. Therefore, the conclusions about the fulfillment of strength requirements by the samples studied are in agreement 
regardless of the criteria (yield strength or UTS) taken into account. Anyhow, it should be taken into account that the final degree of total deformation of a rolling schedule can have a stronger influence on the balance of mechanical properties than the deformation degree of the single passes.

Figure 9a presents an example of TEM image taken from the sample quenched just after reheating. At this stage, precipitates with mostly square or rectangular shapes and sizes generally smaller than $40 \mathrm{~nm}$ can be observed. Cuboidal shapes are typical of titanium nitrides or, in general, (Ti, N)-rich carbonitrides with a certain amount of Nb [32, 40]. It is known that these precipitates are more stable (i.e. their solubility temperature is higher) than niobium or vanadium carbonitrides [40, 52]. The analysis of diffraction patterns and EDX spectra (Fig. 9b) confirms that these particles present in the steel from reheating temperature are ( $\mathrm{Ti}, \mathrm{Nb})$ carbonitrides.

Fig. 10 shows the aspect of precipitates found in the samples quenched at different stages during rolling. Compared to reheating temperature, particle corners are more rounded at lower temperatures, as can be seen for example in Fig. 10a, which corresponds to a quenching temperature of $1075^{\circ} \mathrm{C}$, i.e. at the end of Phase 1 . Spherical/irregular shapes have been previously attributed to $(\mathrm{Ti}, \mathrm{Nb})$ carbides [32]. The well-defined cuboidal shapes of TiN particles formed at high temperatures are more rounded for rising contents of $\mathrm{Ti}$ in steel (which facilitate TiCN precipitation) and particularly for increasing $\mathrm{Nb}$ additions, which cause TiNbCN precipitation [69]. According to the theoretical expressions of solubility temperatures [52], the precipitation models for multicomponent systems [70-72] and experimental measurements of lattice parameters [44] the complex (Ti, Nb) carbonitride would tend to higher ratios of (NbC) for decreasing temperatures and consequently to rounder shapes. Besides, it has been previously observed that TiN precipitated at high temperatures can serve as a "core" for the heterogeneous nucleation and epitaxial growth at lower temperatures of a relatively spherical "cap" or "shell” of TiNbCN rich in Nb and C $[44,71,73,74]$. Nevertheless, coalescence or coarsening of TiNbCN precipitates during the interphase cooling between $1075{ }^{\circ} \mathrm{C}$ and $870{ }^{\circ} \mathrm{C}$ was not remarkable and consequently the austenite grain coarsening at this stage (Fig. 4e) was minor. It is interesting to note that, apart from the relatively coarse Ti-rich particles found from reheating temperature, a second group of very fine dispersed precipitates can be observed at low temperatures, below $870{ }^{\circ} \mathrm{C}$. Fig. 10b illustrates the large difference in sizes of both populations and Fig. 10c shows the very fine and uniform average size of these precipitates at $870{ }^{\circ} \mathrm{C}$. These small particles are hardly found at $1075^{\circ} \mathrm{C}$, so it can be concluded that they have nucleated at a certain temperature within the cooling step of 410 s between phases 1 and 2 (see Table 3). The wide range of precipitate sizes in both populations can equally be observed in Fig. 10d, taken from the sample quenched at the end of Phase 2, i.e. at $810^{\circ} \mathrm{C}$.

The relatively coarser and usually more cuboidal particles found from reheating temperatures contain in some cases a certain fraction of Mo, as can be seen in the EDX spectra of Fig. 9c and Fig. 11a. On the other hand, the finer and rather spherical particles formed at lower temperatures are (Nb, Mo)-rich carbonitrides that do not contain Ti, as shown in Fig. 11b. Molybdenum carbide is very soluble in austenite, more than vanadium carbide [75]. Substantial discrepancies have been found in the predicted solubilities and stoichiometries of the molybdenum carbides in austenite [76]. Mo-rich carbides can be found in pipeline steels, but these particles are often assumed to precipitate in the ferritic domain [40]. For example, Yuan et al [42] did not find strain induced precipitation of Mo carbonitrides at $850{ }^{\circ} \mathrm{C}$ in a low carbon steel with a single addition of $0.33 \%$ Mo. The precipitation of pure Mo carbides at temperatures near 1000 ${ }^{\circ} \mathrm{C}$ appears as improbable for typical low-carbon, low-alloy compositions of pipeline steels with single additions of Mo [36]. However, Kanazawa suggested the presence of pure Mo carbides in austenite at $900{ }^{\circ} \mathrm{C}$ in a steel with $0.12 \% \mathrm{C}$ $0.54 \% \mathrm{Mo}$ and L'Ecuyer [45] found strain-induced carbides in samples deformed and quenched from $875{ }^{\circ} \mathrm{C}$ in a 0.05\%C $0.29 \% \mathrm{Mo}$ steel, even though both authors cannot identify the stoichiometry of the particles. Aronsson [75] estimated that, depending on the composition, Mo carbides would be dissolved around $800{ }^{\circ} \mathrm{C}-900{ }^{\circ} \mathrm{C}$. Quantitative references to the solubility product of pure Mo carbides in austenite are scarce. Ashby et al [77] suggested the following equation for the solubility product (Ks) of $\mathrm{Mo}_{2} \mathrm{C}$ as a function of temperature (T):

$\log \mathrm{Ks}=5.00-7375 / \mathrm{T}$

According to this expression, the solubility temperature for Mo carbide in the low-carbon steel studied would be lower than $900^{\circ} \mathrm{C}$. However, part of the carbon would be consumed by NbCN precipitation at higher temperatures and it has been seen that Mo is present in the complex particles formed at high temperatures (Fig. 9c). Both factors would lower the amount of Mo in solution so it can be expected that pure Mo carbides would be rare or inexistent in the austenite in this steel. Therefore, the presence of Mo in coarser precipitates (Figs. 9c, 11a) can come from small Mo-rich complex carbide particles heterogeneously nucleated on previously existing ( $\mathrm{Nb}, \mathrm{Ti}$ ) carbonitrides $[13,45,78]$ although the existence of cubic Mo nitrides containing microalloying elements at temperatures as high as $1200{ }^{\circ} \mathrm{C}$ has also been suggested [43]. Otherwise, it may happen that Mo replace $\mathrm{Nb}$ or $\mathrm{Ti}$, i.e. Mo is interchangeable in the precipitate lattice, as happens with the combinations of $\mathrm{V}, \mathrm{Nb}$ and $\mathrm{Ti}$ that form complex face-centered cubic (f.c.c.) carbonitrides [11, 13, 32, 39, 42, 78, 79]. The fine particles detected in austenite at lower temperatures (Fig. 11b) are most probably complex $\mathrm{Nb}$ carbonitrides where Mo is introduced in the lattice. In fact, several references indicate that Ti/Nb carbonitrides and carbides precipitated in the austenite are significantly complex in nature and can also have a certain amount of Mo [39, 43-46] even though reported mean sizes are usually coarser than those found in this work. 
No major differences in terms of precipitate morphology, distribution or composition were found between the samples corresponding to two different levels of accumulated stress at the end of hot rolling. In both cases, the coarser particles tend to be rectangular-shaped with significantly smoothed corners and they appear sometimes coalesced (Fig. 12). Coarse precipitates are rich in Ti-Nb, whereas the distribution of fine globular particles corresponds to NbMo carbonitrides.

More than 400 particles were measured and counted in all samples studied by TEM in order to obtain frequency distributions of sizes like the example shown in Figure 13a for reheating temperature. The mean size after reheating at $1150{ }^{\circ} \mathrm{C}(21 \mathrm{~nm})$ is close to the results previously found for low carbon steels with similar Ti content and Ti/N ratio [80]. Due to their different nature and distribution, the coarser and finer precipitates (the latter appearing only at lower temperatures) where divided into two populations and measured separately (Figs. 13b and 13c). As can be seen in Figure 14, the mean size of the coarser $(\mathrm{Ti}, \mathrm{Nb}$ ) precipitates does not vary significantly during rolling and maintains a rather constant value between 20 and $30 \mathrm{~nm}$. The mean size grows slightly from reheating temperature $\left(1150{ }^{\circ} \mathrm{C}\right)$ to the first deformation temperature studied $\left(1075^{\circ} \mathrm{C}\right)$. Probably, strain induced precipitation partially takes place by the aforementioned nucleation of TiNbCN precipitates richer in $\mathrm{NbC}$ on pre-existing cuboidal particles [73]. This can simultaneously round-off and coarsen the particles formed at high temperatures. On the other hand, the average size of the finest (Nb, Mo) precipitates stays near 4-6 nm. Similar results have been found by other authors in X70 pipeline steels, i.e. the existence of two distinct populations of precipitates: coarser cuboidal carbonitrides rich in TiN that form above $1150^{\circ} \mathrm{C}$ and finer and more spherical NbC-based precipitates that form between $1100^{\circ} \mathrm{C}$ and $900{ }^{\circ} \mathrm{C}[74,81]$, even though they measured a coarser mean particle size than in this work. On the other hand, previous studies on X-100 steels describe fine precipitates having average sizes near 4-5 nm with a remarkable presence of Mo together with smaller amounts of other microalloying elements substituting $\mathrm{Nb}$ [33, 41]. In particular, the results shown in Fig 13c are very similar to the size distribution reported for fine Nb-Mo rich precipitates (essentially carbides) that start to form between $950-1050^{\circ} \mathrm{C}$ in a X-100 steel [41]. On the other hand, the constant value of mean particle size measured throughout hot rolling is in agreement with previous works [30] that found that the precipitate size can strongly decrease during hot rolling when long interpass times that allow particle coarsening at high temperatures are used, but mean size is roughly constant throughout rolling if a short interpass time as those used in present work is applied. Finally, it should be taken into account that, as happened with the precipitate shape, distribution or composition, the level of strengthening at the end of hot rolling (value of $\Delta \sigma$ ) does not play an important influence on the mean size of both coarse and fine particles, as can be seen in Fig. 14. Therefore, the changes in hardness and strength values observed after cooling can be mostly attributed to the different microstructures achieved depending on austenite strengthening.

\section{CONCLUSIONS}

Hot torsion rolling simulation tests were carried out on samples of a low-carbon CMnNbMoTi pipeline steel following a close-to-industrial schedule. These tests combined with quench-interrupted tests allowed to study the evolution of austenite microstructure and precipitation state during thermomechanical processing, as well as the influence of austenite strengthening below $\mathrm{T}_{\mathrm{nr}}$ (characterized by the value of accumulated stress $\Delta \sigma$ ) on final microstructure. The main conclusions are as follows:

- The fine initial austenite grain size obtained after reheating (below $20 \mu \mathrm{m}$ ) facilitates the complete recrystallization during Phase I (roughing). A slight growth of recrystallized grain size can happen during the long cooling interval between Phases 1 and 2. Phases 2 and 3 where finishing passes are applied let to achieve an increasingly strengthened austenite, as shown in the values of MFS, $\Delta \sigma$ and grain elongation.

- The high density of potential nucleation sites for ferrite (dislocations, grain boundaries) in hardened austenite can allow a minor degree of intercritical deformation at lower temperatures. On the other hand, static restoration can occur during the cooling time between Phases 2 and 3. Both factors help to explain the relative softening (slight drop in the value of MFS) observed in the last hot rolling simulation passes.

- Ferrite grains obtained after cooling are finer and more equiaxed when austenite is more heavily deformed in the final passes (higher values of $\Delta \sigma$ ) due to the higher density of ferrite nucleation sites. On the other hand, lower values of $\Delta \sigma$ (i.e. less severe deformation of austenite in final rolling passes) generate more acicular structures after cooling. This behavior is observed both after slow and very fast cooling.

- Consequently, the hardness of the samples decreases for increasing values of $\Delta \sigma$ and this happens with a similar trend for both cooling rates. Correspondingly, higher strength can be expected in the steel when austenite is less severely deformed in the last passes just before final cooling.

- (Ti, Nb) carbonitrides with mostly cuboidal shapes and mean sizes between 20 and $30 \mathrm{~nm}$ can be observed from reheating temperature $\left(1150^{\circ} \mathrm{C}\right)$ to the end of hot rolling. These precipitates present higher ratios of $\mathrm{Nb}$ and $\mathrm{C}$ and rounder shapes for decreasing rolling temperatures and occasionally they contain Mo. Heterogeneous nucleation of more soluble precipitates on more stable TiN particles seems to take part in the formation of these particles. 
- A second family of very fine (4-6 nm) round precipitates nucleate within the cooling step between roughing and finishing phases, i.e. between $1075^{\circ} \mathrm{C}$ and $870{ }^{\circ} \mathrm{C}$. These particles have been identified as Ti-free, complex $\mathrm{Nb}$ carbonitrides where Mo is introduced in the lattice.

- Both types of precipitates keep a fairly constant mean size throughout hot rolling simulation. Provided that Phase 1 and 2 are identical, the accomplishment of different levels of accumulated stress at the end of hot rolling schedule does not introduce major differences in precipitate morphology, nature, size and distribution, so the changes in hardness values can be mostly attributed to the different microstructures achieved. 


\section{REFERENCES}

[1] H. G. Hillenbrand, C. Kalwa, World Pipelines 2 (2002) 57-61.

[2] Y.-K. Wang, J.-H. Pan, K. Yang, Y. Shan, in: Proceedings of International Symposium on Microalloyed Steels for the Oil and Gas Industry, Araxa, TMS, 2007, pp. 135-179.

[3] K. T. Corbett, R. R. Bowen, C. W. Petersen, Int. J. Offshore Polar Eng. 14 (2004) 75-80.

[4] I. D. S. Bott, L. F. G. De Souza, J. C. G. Teixeira, P. R. Rios, Metall. Mater. Trans. A 36A (2005) $443-454$.

[5] K. Junhua, Z. Lin, G. Bin, L. Pinghe, W. Aihua, X. Changsheng, Mater. Des. 25 (2004) 723-728.

[6] W. Wang, Y. Shan, K. Yang, Mater. Sci. Eng. A 502 (2009) 38-44.

[7] A. Takahashi, M. Iino, ISIJ Int. 36 (2) (1996) 241-245

[8] F.-R. Xiao, B. Liao, Y.-Y. Shan, G.-Y. Qiao, Y. Zhong, C. Zhang, K. Yang, Mater. Sci. Eng. A 431 (2006) 4152.

[9] T. Schambron, A. W. Phillips, D. M. O’Brien, J. Burg, E. V. Pereloma, C. C. Killmore, J. A. Williams, ISIJ Int. 49 (2009) 284-292

[10] Y. B. Xu, Y. M. Yu, B. L. Xiao, Z. Y. Liu, G. D. Wang. J. Mater. Sci. 44 (2009) 3928-3935.

[11] J. Y. Koo, M. J. Luton, N. V. Bangaru et al., Int. J. Offshore Polar Eng. 14 (2004) 2-10.

[12] C. I. Garcia, K. Cho, M. Hua, A. J. DeArdo, Mater. Sci. Forum 638-642 (2010), 124-129.

[13] S. Shanmugam, R. D. K. Misra, J. Hartmann, S. G. Jansto, Mater. Sci. Eng. A 441 (2006) 215-229.

[14] I. A. Yakubtsov, P. Poruks, J. D. Boyd, Mater. Sci. Eng. A 480 (2008) 109-116.

[15] Y. Smith, A. Coldren, R. Cryderman, Met. Sci. Heat Treat. 18 (1976) 59-65.

[16] A. P. Coldren, J. L. Mihelich, Met. Sci. Heat Treat. 19 (1977) 559-572.

[17] T. Tanaka, Int. Met. Rev. 26 (1981) 185-212.

[18] M.-C. Zhao, K. Yang, Y. Shan, Mater. Sci. Eng. A 335 (2002) 14-20.

[19] M.-C. Zhao, K. Yang, Y.-Y. Shan, Mater. Lett. 57 (2003) 1496-1500.

[20] Y. M. Kim, H. Lee, N. J. Kim, Mater. Sci. Eng. A 478 (2008) 361-370.

[21] K. Wu, Z. Li, A. M. Guo, X. He, L. Zhang, A. Fang, L. Cheng, ISIJ Int. 46 (2006) 161-165.

[22] S. Y. Shin, S. Y. Han, B. Hwang, C. G. Lee, S. Lee, Mater. Sci. Eng. A 517 (2009) 212-218.

[23] A. Guo, R. D. K. Misra, J. Xu, B. Guo, S. G. Jansto. Mater. Sci. Eng. A 527 (2010) 3886-3892.

[24] M.-C. Zhao, K. Yang, F.-R. Xiao, Y.-Y. Shan, Mater. Sci. Eng. A 355 (2003) 126-136.

[25] J.-H. Yang, Q.-Y. Liu, D.-B. Sun, X.-Y. Li, J. Iron Steel Res. Int. 17 (2010) 53-59.

[26] Z. Tang, W. Stumpf, Mater. Charact. 59 (2008) 717-728

[27] P. P. Suikkanen, J. I. Kömi, L. P. Karjalainen, Met. Sci. Heat Treat. 47 (2005) 507-511.

[28] M. Gomez, O. Hernanz, S. F. Medina, P. Tarin. Steel Res. 73 (2002) 446-452.

[29] S. F. Medina, M. Gómez, E. Rodríguez, L. Rancel, ISIJ Int. 48 (2008) 1263-1269.

[30] M. Gómez, S. F. Medina, P. Valles, ISIJ Int. 45 (2005) 1711-1720.

[31] R. Wang, C. I. Garcia, M. Hua, K. Cho, H. Zhang, A. J. DeArdo, ISIJ Int. 46 (2006) 1345-1353.

[32] S. Shanmugam, N. K. Ramisetti, R. D. K. Misra, J. Hartmann, S.G. Jansto, Mater. Sci. Eng. A 478 (2008) 2637.

[33] J. Lu, H. Henein, D. G. Ivey, in: Conf. Proc. Materials Science and Technology MS\&T’07, Automotive Symposium, ed. by R. E. Ashburn, AIST, Warrendale, PA, 2007, pp. 123-134.

[34] H. L. Andrade, M. G. Akben, J. J. Jonas, Metall. Trans. A 14A (1983) 1967-1977.

[35] S. F. Medina, A. Quispe, M. Gomez, Mater. Sci. Technol. 19 (2003) 99-108.

[36] B. Bacroix, M. G. Akben, J. J. Jonas, in: A. J. DeArdo, G. A. Ratz, P. J. Wray, (eds.), Proc. International Symposium Thermomechanical Processing of Microalloyed Austenite, TMS-AIME, Warrendale, PA, 1981, pp. 293-318.

[37] B. Pereda, B. López, J. M. Rodriguez-Ibabe, in: A. J. DeArdo, C. I. Garcia (eds.), Proc. International Conference on Microalloyed Steels: Processing, Microstructure, Properties and Performance, Pittsburgh, AIST, Warrendale, PA, 2007, pp. 151-159.

[38] P. Uranga, B. Lopez, J. M. Rodriguez-Ibabe, Mater. Sci. Technol. 25 (2009) 1147-1153.

[39] S. Kanazawa, A. Nakashima, K. Okamoto, K. Tanabe, S. Nakazawa, Trans. JIM 8 (1967) 113-120.

[40] K. Banerjee, M. Militzer, M. Perez, X. Wang, Metall. Mater. Trans. A 41 (2010) 3161-3172.

[41] K. Poorhaydari, D.G. Ivey, Can. Metall. Q. 48 (2009) 115-122.

[42] S.-Q. Yuan, G.-L. Liang, X.-J. Zhang, J. Iron Steel Res. Int. 17 (2010) 60-63.

[43] S. K. Mishra(Pathak), S. Das, S. Ranganathan, Mater. Sci. Eng. A 323 (2002) 285-292.

[44] S. Akhlaghi, D. G. Ivey, Can. Metall. Q. 41 (2002) 111-119.

[45] J. D. L'Ecuyer, G. L’Esperance, M. G. Akben, B. Bacroix, Acta metall. 35 (1987) 1149-1158.

[46] W. B. Lee, S. G. Hong, C. G. Park, K. H. Kim, S. H. Park, Scripta mater. 43 (2000) 319-324.

[47] S. Yamamoto, C. Ouchi, T. Osuka, in: A. J. DeArdo, G. A. Ratz, P. J. Wray, (eds.), Proc. International Symposium Thermomechanical Processing of Microalloyed Austenite, TMS-AIME, Warrendale, PA, 1981, pp. 613-639.

[48] M. I. Vega, S. F. Medina, A. Quispe, M. Gomez, P. P. Gomez, Mater. Sci. Eng. A 423 (2006) $253-261$.

[49] F. H. Samuel, S. Yue, J. J. Jonas, B. A. Zbinden, ISIJ Int. 29 (1989) 878-886.

[50] J. Calvo, L. Collins, S. Yue, ISIJ Int. 50 (2010) 1193-1199. 
[51] M. Gómez, P. Valles, S.F. Medina, in: Proceedings of the Int. Conf. Metal 2010, Roznov pod Radhostem, Czech Republic, 2010.

[52] E. T. Turkdogan, Iron Steelmaker 16 (1989) 61-75.

[53] M. Gómez, L. Rancel, B. J. Fernández, S. F. Medina, Mater. Sci. Eng. A 501 (2009) 188-196.

[54] A. Faessel, Rev. Métall. Cah. Inf. Tech. 33 (1976) 875-892.

[55] M. Gómez, S. F. Medina, G. Caruana, ISIJ Int. 43 (2003) 1228-1237.

[56] C. Ouchi, T. Sampei, I. Kozasu, Trans. Iron Steel Inst. Jpn. 22 (1982) 214-222.

[57] P. A. Manohar, T. Chandra, C. R. Killmore, ISIJ Int. 36 (1996) 1486-1493.

[58] H. J. Jun, J. S. Kang, D. H. Seo, K. B. Kang, C. G. Park, Mater. Sci. Eng. A 422 (2006) 157-162.

[59] Z. Zhao, Z. Wang, H. Zhang, L. Qiao, J. Univ. Sci. Technol. Beijing 14 (2007) 410-413.

[60] T. Siwecki, G. Engberg, P. Hansson, Scand. J. Metall. 31 (2002) 342-352

[61] Deutsches Institut für Normung, DIN 50150 German standard, 1982.

[62] J. R. Cahoon, W. H. Broughton, A. R. Kutzak, Metall. Trans. 2 (1971) 1979-1983.

[63] C.-Y. Hsu, J. Nucl. Mater. 141-143 (1986) 518-522.

[64] M. O. Lai, K. B. Lim, J. Mater. Sci. 26 (1991) 2031-2036.

[65] I. A. Yakubtsov, P. Poruks, J. D. Boyd, Mater. Sci. Eng. A 480 (2008) 109-116.

[66] M. Zhou, L. Du, X. Liu, Acta Metall. Sin. (Engl. Lett.) 23 (2010) 171-175.

[67] W. K. Kim, H. G. Jung, G. T. Park, S. U. Koh, K. Y. Kim, Scripta Mater. 62 (2010) 195-198.

[68] H. G. Hillenbrand, C. J. Heckmann, K. A. Niederhoff, in: Proceedings APIA 2002 Annual Conference, X80 Pipeline Cost Workshop, Hobart, Australia, 2002, pp. 35-49.

[69] A. P. Coldren, R. L. Cryderman, M. Semchyshen, in: Steel-Strengthening Mechanisms, Climax Molybdenum Company, Zurich, 1969, pp. 17-44.

[70] M. Hillert, L. I. Staffanson, Acta Chem. Scand. 24 (1970) 3618-3626.

[71] S. Zajac, B. Jansson, Metall. Mater. Trans. B 29B, (1998) 163-176.

[72] J. M. Cabrera, A. Al Omar, J. M. Prado, J. Mater. Sci. 31 (1996) 1303-1309.

[73] A. J. Craven, K. He, L. A. J. Garvie, T. N. Baker, Acta Mater. 48 (2000) 3869-3878

[74] H. Yu, Y. Sun, Q. Chen, H. Jiang, L. Zhang, J. Univ. Sci. Technol. Beijing 13 (2006) 523-527.

[75] B. Aronsson, in: Steel-Strengthening Mechanisms, Climax Molybdenum Company, Zurich, 1969, pp. 77-87.

[76] T. Wada, H. Wada, J. F. Elliott, J. Chipman, Metall. Trans. 3 (1972) 2865-2872.

[77] M. F. Ashby, K. E. Easterling, Acta Metall. 30 (1982) 1969-1978.

[78] R. D. K. Misra, G. C. Weatherly, J. E. Hartmann, A. J. Boucek, Mater. Sci. Technol. 17 (2001) 1119-1129.

[79] T. N. Baker, Y. Li, J. A. Wilson, A. J. Craven, D. N. Crowther, Mater. Sci. Technol. 20 (2004) 720-730.

[80] M. I. Vega, S. F. Medina, A. Quispe, M. Gómez, P. P. Gómez, ISIJ Int. 45 (2005) 1878-1886.

[81] C. Wang, X. Wu, J. Liu, R. A. Xu. J. Univ. Sci. Technol. Beijing 28 (2006) 253-258. 
Table 1. Chemical composition of steel studied (mass\%).

\begin{tabular}{|c|c|c|c|c|c|c|c|c|c|c|c|c|}
\hline $\mathrm{C}$ & $\mathrm{Si}$ & $\mathrm{Mn}$ & $\mathrm{S}$ & $\mathrm{P}$ & $\mathrm{Al}$ & $\mathrm{Mo}$ & $\mathrm{Ni}$ & $\mathrm{Cu}$ & $\mathrm{Cr}$ & $\mathrm{Nb}$ & $\mathrm{Ti}$ & $\mathrm{N}$ \\
\hline 0.056 & 0.31 & 1.90 & 0.0015 & 0.011 & 0.029 & 0.213 & 0.221 & 0.193 & 0.044 & 0.046 & 0.018 & 0.0044 \\
\hline
\end{tabular}

Table 2. Calculated solubility temperatures $\left({ }^{\circ} \mathrm{C}\right)$ for the steel studied [52].

\begin{tabular}{|c|c|c|c|c|}
\hline $\mathrm{NbC}_{0.87}$ & $\mathrm{NbN}$ & $\mathrm{NbC}_{0.7} \mathrm{~N}_{0.2}$ & $\mathrm{TiC}$ & $\mathrm{TiN}$ \\
\hline 1068 & 1083 & 1116 & 945 & 1389 \\
\hline
\end{tabular}

Table 3. Hot torsion rolling simulation schedules carried out in the study.

\begin{tabular}{|c|c|c|c|c|}
\hline Phase & Pass number & Pass strain & Interpass time $(\mathrm{s})$ & Temperature $\left({ }^{\circ} \mathrm{C}\right)$ \\
\hline Reheating & \multicolumn{5}{|l|}{} & $1150 \times 15$ min \\
\hline 1 & $1-11$ & 0.1 & 10 & $1125-1075$ \\
\hline Interval 1-2 (410 s) & $12-15$ & 0.3 & 10 & $870-810$ \\
\hline 2 & \multicolumn{5}{|l}{} \\
\hline Interval 2-3 (60 s) & 16 & 0.1 & & 750 \\
\hline 3a (low $\Delta \sigma)$ & 16 & 0.25 & 5 & 750 \\
\hline 3b (medium $\Delta \sigma)$ & 16 & 0.3 & & 750 \\
\hline 3c (high $\Delta \sigma)$ & 17 & 0.3 & & \\
\cline { 2 - 5 } & &
\end{tabular}

Table 4. Quenching conditions along the schedule shown in Table 3 chosen to study the evolution of austenite microstructure and precipitation state.

\begin{tabular}{|c|l|}
\hline Quench temp. $\left({ }^{\circ} \mathrm{C}\right)$ & Quench-deformation conditions \\
\hline 1150 & After reheating $1150^{\circ} \mathrm{Cx} 15$ min \\
\hline 1105 & Before deformation \\
\hline 1100 & After deformation, strain $=0.1$ \\
\hline 1075 & After deformation, strain $=0.1$ \\
\hline \multicolumn{2}{|c|}{ (Cooling interval, 410 s) } \\
\hline 870 & Before deformation \\
\hline 810 & After deformation, strain $=0.3$ \\
\hline \multicolumn{2}{|l}{ (Cooling interval, 60 s) } \\
\hline 750 & After deformation, strain $=0.1($ low $\Delta \sigma)$ \\
\hline 750 & After deformation, strain $=0.25($ medium $\Delta \sigma)$ \\
\hline 760 & Before deformation \\
\hline 750 & After deformation, strain $=0.3($ high $\Delta \sigma)$ \\
\hline
\end{tabular}




\section{FIGURE CAPTIONS}

Figure 1. Mean Flow Stress (MFS) versus the inverse of absolute temperature according to a hot rolling simulation schedule using average values for strain, strain rate and interpass time.

Figure 2. MFS versus the inverse of absolute temperature according to the schedules shown in Table 3.

Figure 3. Dilatometric curve during cooling of the steel studied. The first and second derivatives of the dilation curve are included to facilitate the identification of $\mathrm{A}_{\mathrm{r} 3}$ temperature.

Figure 4. Evolution of austenite microstructure during hot rolling simulation. "Td" means temperature of the last deformation applied and "Tq" means quenching temperature. Etchant: picric acid + wetting agent. a) Sample quenched after reheating $\left(1150^{\circ} \mathrm{C}\right.$ x $\left.15 \mathrm{~min}\right)$; b) $\mathrm{Td}=\mathrm{Tq}=1105^{\circ} \mathrm{C}$; c) $\left.\mathrm{Td}=1105^{\circ} \mathrm{C}, \mathrm{Tq}=1100{ }^{\circ} \mathrm{C} ; \mathbf{d}\right) \mathrm{Td}=\mathrm{Tq}=1075^{\circ} \mathrm{C}$; e) $\mathrm{Td}$ $\left.\left.=1075^{\circ} \mathrm{C}, \mathrm{Tq}=870{ }^{\circ} \mathrm{C} ; \mathbf{f}\right) \mathrm{Td}=\mathrm{Tq}=810^{\circ} \mathrm{C} ; \mathbf{g}\right) \mathrm{Td}=810^{\circ} \mathrm{C}, \mathrm{Tq}=760{ }^{\circ} \mathrm{C}$.

Figure 5. Microstructure at the end of hot rolling simulation. Samples quenched from $750{ }^{\circ} \mathrm{C}$ after deformation. Etchant: picric acid + wetting agent. a) Sample corresponding to schedule 3a in Table 3 (low $\Delta \sigma$ ); b) Schedule $3 \mathrm{~b}$ (medium $\Delta \sigma$ ); c) Schedule 3c (high $\Delta \sigma$ ).

Figure 6. Microstructure at the end of hot rolling simulation observed by optical microscopy (left) and SEM (right). Samples quenched from $750{ }^{\circ} \mathrm{C}$ after deformation. Etchant: nital. a) b) Sample corresponding to schedule $3 a$ in Table 3 (low $\Delta \sigma)$; c) d) Schedule 3c (high $\Delta \sigma$ ).

Figure 7. Microstructure at the end of hot rolling simulation observed by optical microscopy (left) and SEM (right). Samples slowly cooled under an argon flow from $750{ }^{\circ} \mathrm{C}$ after deformation. Etchant: nital. a) b) Sample corresponding to schedule 3a in Table 3 (low $\Delta \sigma$ ); c) d) Schedule 3c (high $\Delta \sigma$ ).

Figure 8. Values of Vickers Microhardness (HV) as a function of accumulated stress $(\Delta \sigma)$ obtained at the end of hot

rolling simulation. $\mathrm{HV}$ was measured on samples water-quenched and slowly cooled in argon from $750{ }^{\circ} \mathrm{C}$ after following hot rolling simulation schedules 3a, 3b and 3c shown in Table 3. On the right axis, yield strength values are estimated as $\sigma_{\mathrm{y}}=2.6 \mathrm{HV}$ and the lower limits of $\sigma_{\mathrm{y}}$ or "specified minimum yield strengths" (SMYS) for X80 and X90 grade steels are indicated.

Figure 9. Precipitation state after reheating prior to hot rolling simulation. Quenching temperature $=1150{ }^{\circ} \mathrm{C}$. a) $\mathrm{TEM}$ image of carbon replica showing cuboidal precipitates; b) Energy dispersive X-ray (EDX) analysis spectrum of a precipitate showing the presence of $\mathrm{Ti}$ and $\mathrm{Nb}$; c) EDX analysis spectrum of a precipitate showing the presence of $\mathrm{Ti}$, $\mathrm{Nb}$ and Mo.

Figure 10. TEM images showing the evolution of precipitation state during hot rolling simulation schedule. "Td" means temperature of the last deformation applied and "Tq" means quenching temperature. a) End of Phase $1, \mathrm{Td}=\mathrm{Tq}$ $=1075^{\circ} \mathrm{C}$; b) Coarser and finer precipitates at the beginning of Phase $2, \mathrm{Td}=1075{ }^{\circ} \mathrm{C}, \mathrm{Tq}=870{ }^{\circ} \mathrm{C}$; $\mathbf{c}$ ) Detail showing finer precipitates at the beginning of Phase $2, \mathrm{Td}=1075^{\circ} \mathrm{C}, \mathrm{Tq}=870^{\circ} \mathrm{C}$; d) Coarser and finer precipitates at the end of Phase $2, \mathrm{Td}=\mathrm{Tq}=810^{\circ} \mathrm{C}$.

Figure 11. EDX analysis spectra of precipitates found at $810{ }^{\circ} \mathrm{C}$, i.e. the end of Phase 2. a) Coarser particle with Ti, $\mathrm{Nb}$ and Mo; b) Finer and more globular particle with Nb-Mo.

Figure 12. TEM images showing precipitation state obtained at the end of hot rolling simulation. Last deformation temperature $=$ quenching temperature $=750{ }^{\circ} \mathrm{C}$, i.e. at the end of Phase 3 . Two distinct populations of coarse and fine particles can be observed. The coarsest appear sometimes coalesced. a) Phase 3a, lowest $\Delta \sigma$ level; b) Phase 3c, highest $\Delta \sigma$ level.

Figure 13. Examples of precipitate size distribution obtained at different stages of hot rolling simulation. a) After reheating at $1150{ }^{\circ} \mathrm{C}$; b) End of hot rolling, $750{ }^{\circ} \mathrm{C}$, High $\Delta \sigma$, Coarser precipitates; c) End of hot rolling, $750{ }^{\circ} \mathrm{C}$, High $\Delta \sigma$, Finer precipitates.

Figure 14. Evolution of mean precipitate size during the hot rolling simulation shown in Figure 2. 


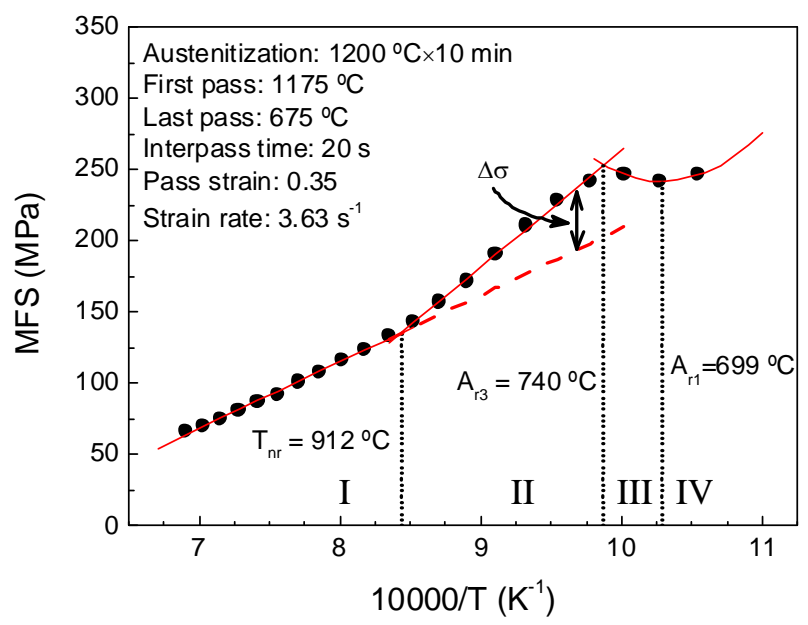

Figure 1. Mean Flow Stress (MFS) versus the inverse of absolute temperature according to a hot rolling simulation schedule using average values for strain, strain rate and interpass time. 


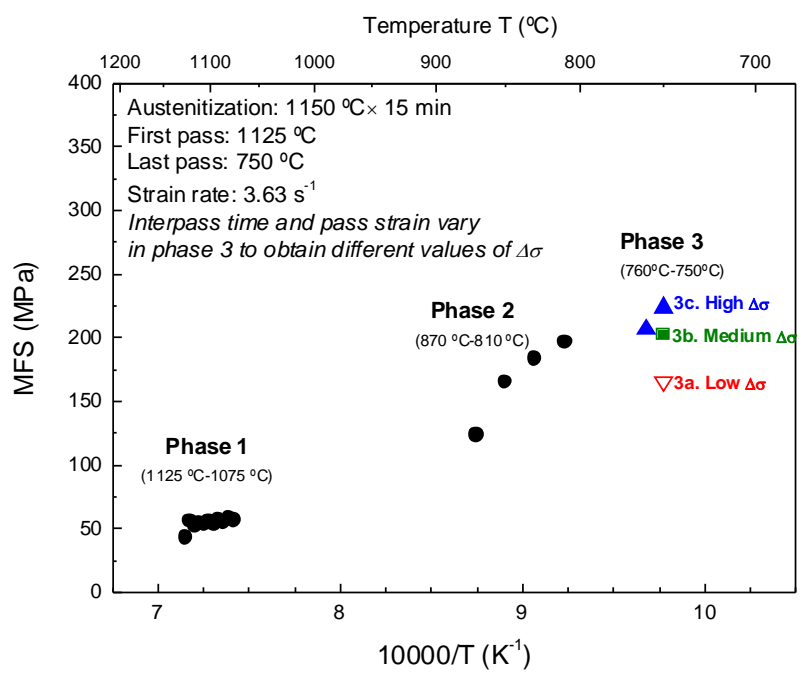

Figure 2. MFS versus the inverse of absolute temperature according to the schedules shown in Table 3. 


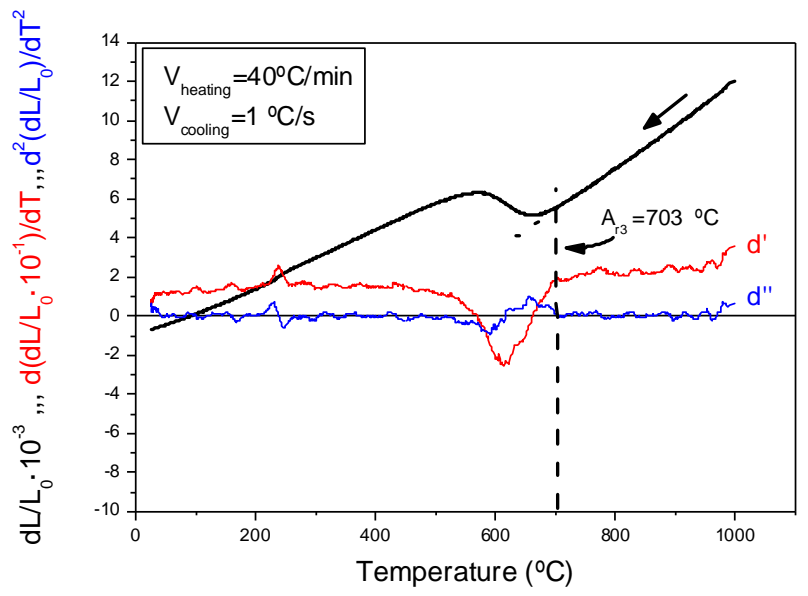

Figure 3. Dilatometric curve during cooling of the steel studied. The first and second derivatives of the dilation curve are included to facilitate the identification of $\mathrm{A}_{\mathrm{r} 3}$ temperature. 


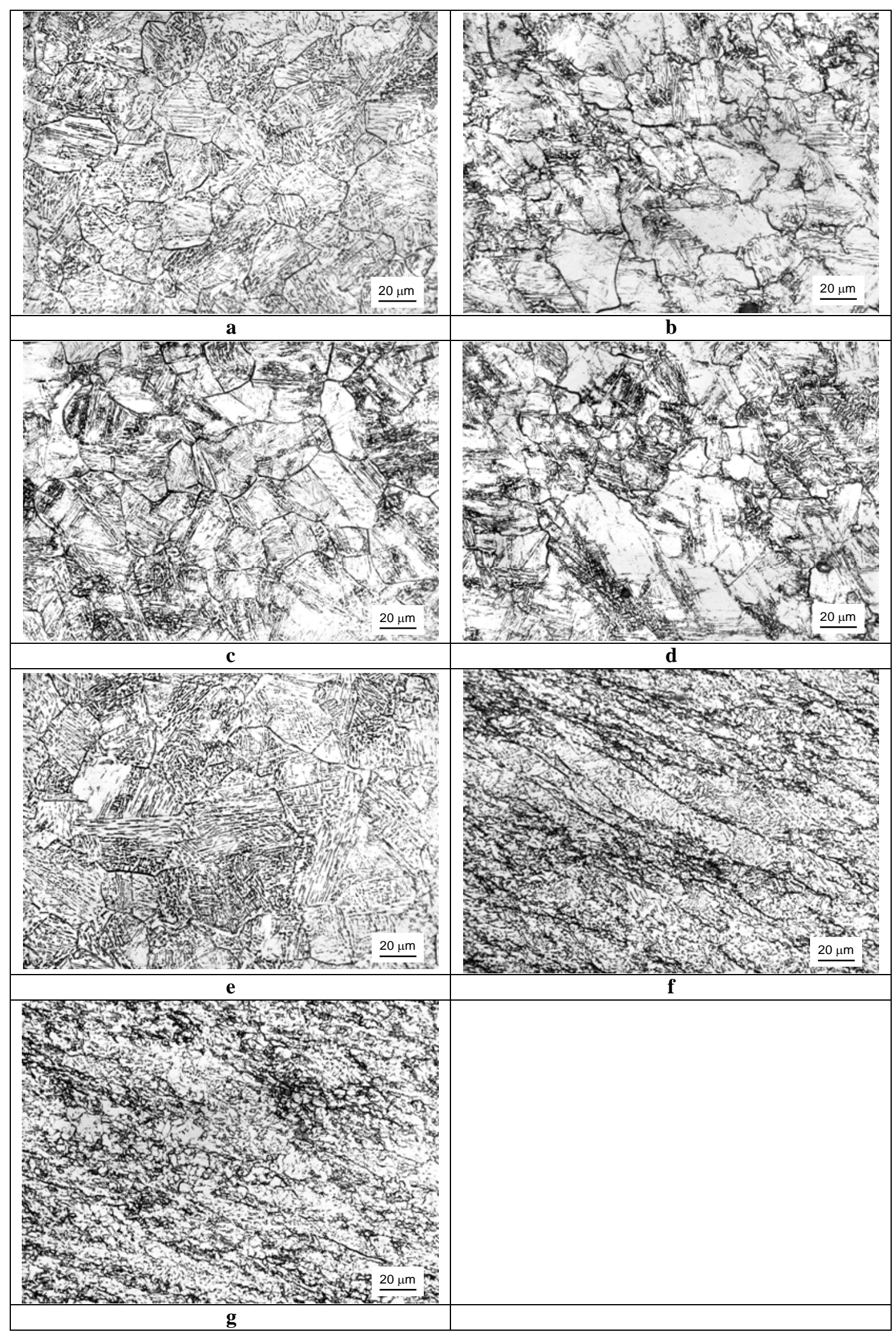

Figure 4. Evolution of austenite microstructure during hot rolling simulation. "Td" means temperature of the last deformation applied and "Tq" means quenching temperature. Etchant: picric acid + wetting agent. a) Sample quenched after reheating $\left(1150{ }^{\circ} \mathrm{C} \times 15 \mathrm{~min}\right)$; b) $\mathrm{Td}=\mathrm{Tq}=1105^{\circ} \mathrm{C}$; c) $\left.\left.\mathrm{Td}=1105^{\circ} \mathrm{C}, \mathrm{Tq}=1100^{\circ} \mathrm{C} ; \mathbf{d}\right) \mathrm{Td}=\mathrm{Tq}=1075^{\circ} \mathrm{C} ; \mathbf{e}\right) \mathrm{Td}$ $\left.\left.=1075^{\circ} \mathrm{C}, \mathrm{Tq}=870^{\circ} \mathrm{C} ; \mathbf{f}\right) \mathrm{Td}=\mathrm{Tq}=810^{\circ} \mathrm{C} ; \mathbf{g}\right) \mathrm{Td}=810^{\circ} \mathrm{C}, \mathrm{Tq}=760^{\circ} \mathrm{C}$. 


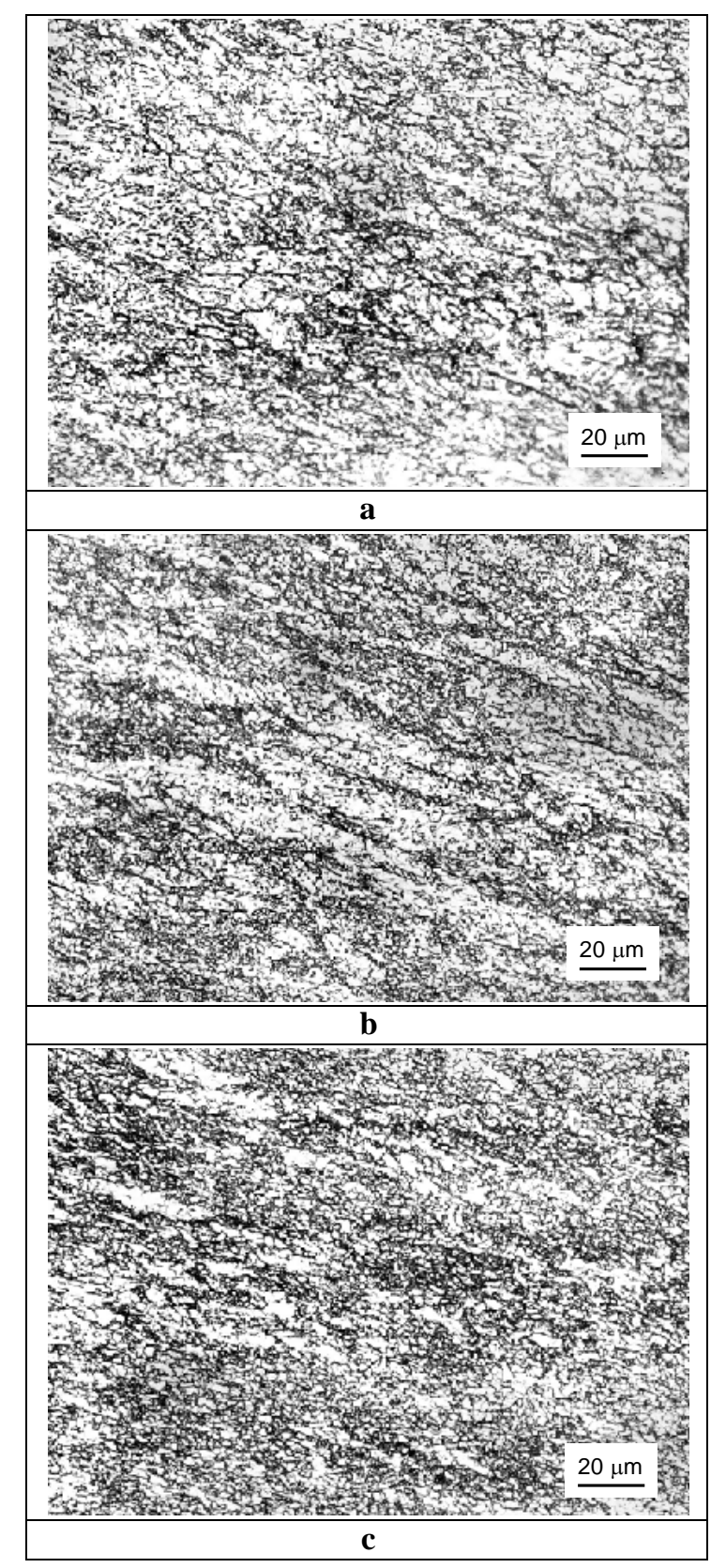

Figure 5. Microstructure at the end of hot rolling simulation. Samples quenched from $750{ }^{\circ} \mathrm{C}$ after deformation. Etchant: picric acid + wetting agent. a) Sample corresponding to schedule 3a in Table 3 (low $\Delta \sigma$ ); b) Schedule $3 \mathrm{~b}$ (medium $\Delta \sigma$ ); c) Schedule 3c (high $\Delta \sigma$ ). 


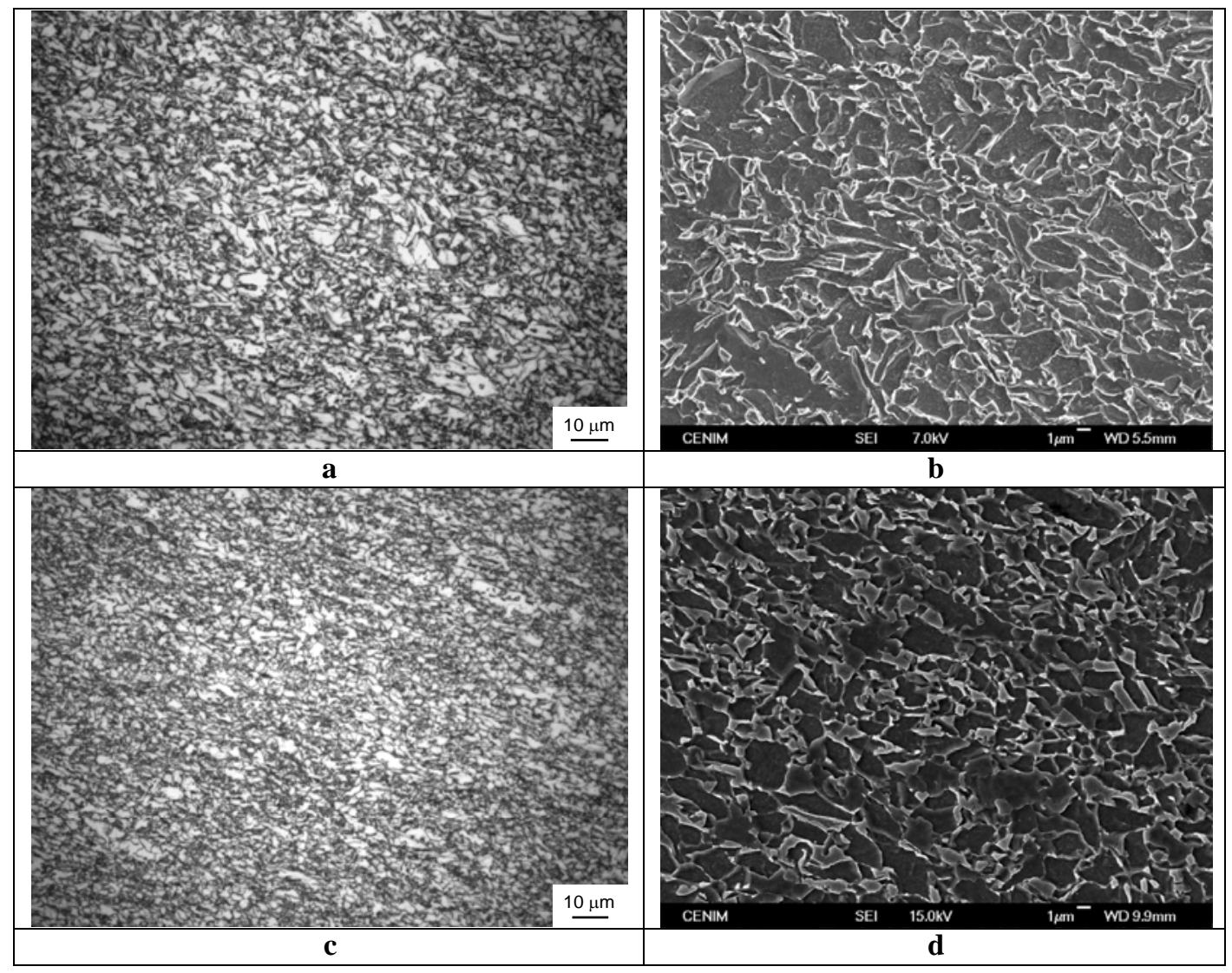

Figure 6. Microstructure at the end of hot rolling simulation observed by optical microscopy (left) and SEM (right). Samples quenched from $750^{\circ} \mathrm{C}$ after deformation. Etchant: nital. a) b) Sample corresponding to schedule 3a in Table 3 (low $\Delta \sigma$ ); c) d) Schedule 3c (high $\Delta \sigma$ ). 


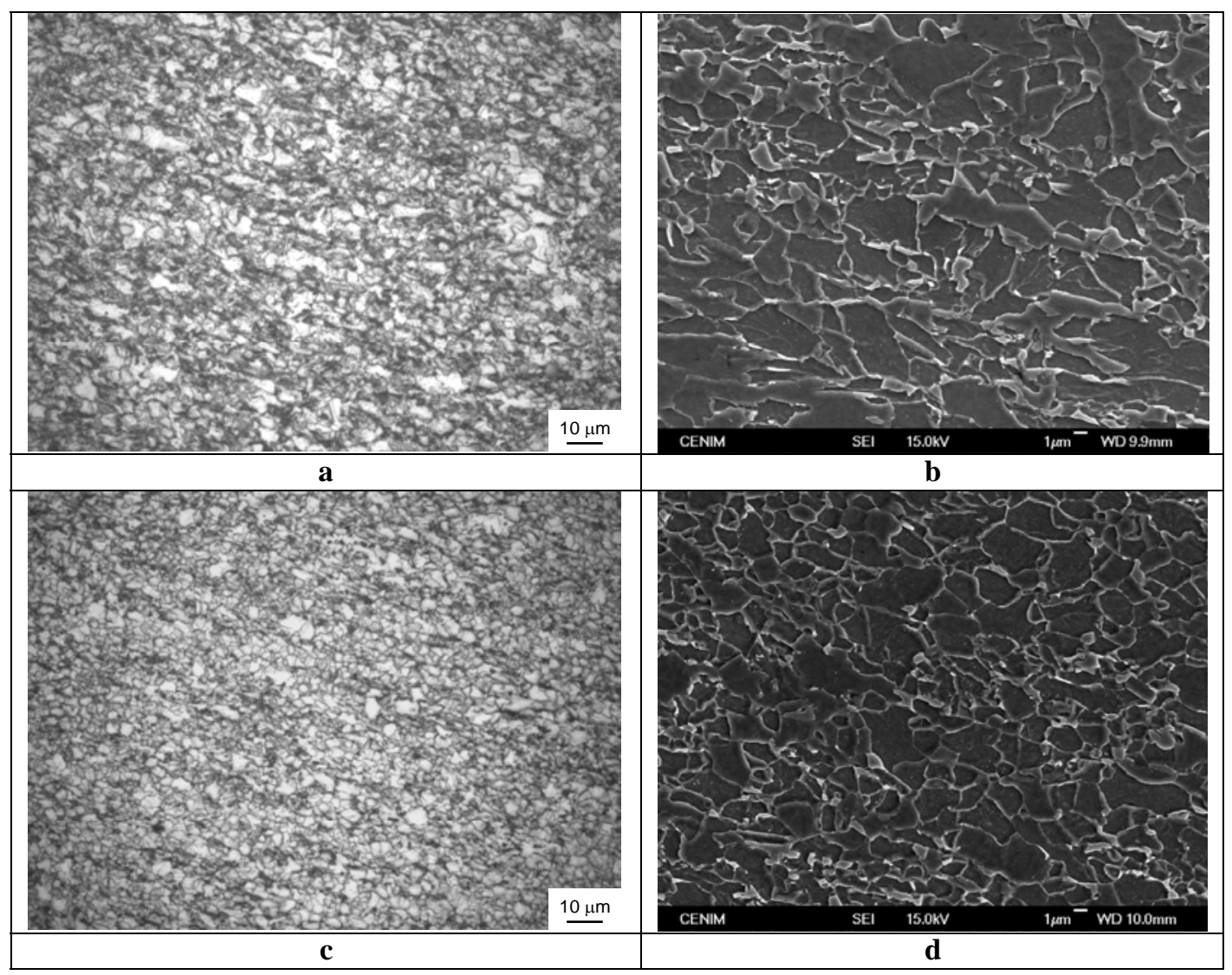

Figure 7. Microstructure at the end of hot rolling simulation observed by optical microscopy (left) and SEM (right). Samples slowly cooled under an argon flow from $750^{\circ} \mathrm{C}$ after deformation. Etchant: nital. a) b) Sample corresponding to schedule 3a in Table 3 (low $\Delta \sigma$ ); c) d) Schedule 3c (high $\Delta \sigma$ ). 


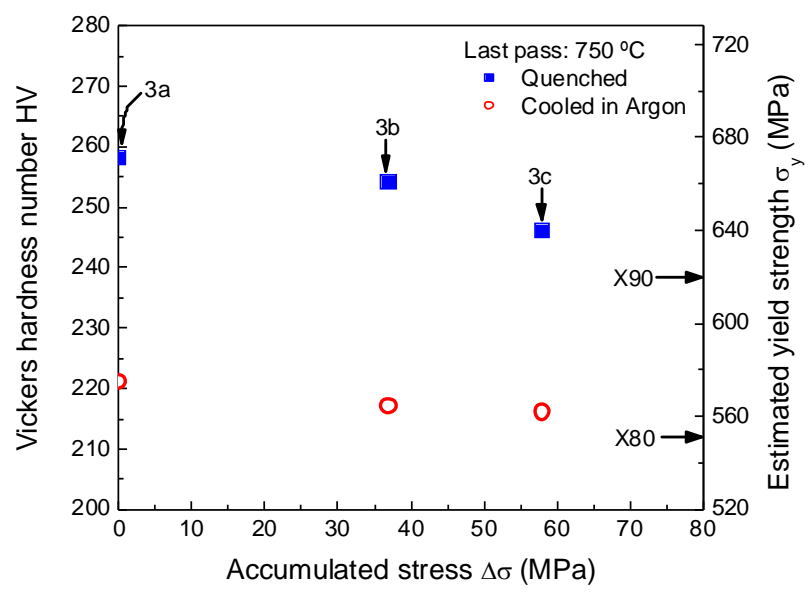

Figure 8. Values of Vickers Microhardness $(\mathrm{HV})$ as a function of accumulated stress $(\Delta \sigma)$ obtained at the end of hot rolling simulation. $\mathrm{HV}$ was measured on samples water-quenched and slowly cooled in argon from $750{ }^{\circ} \mathrm{C}$ after following hot rolling simulation schedules 3a, $3 \mathrm{~b}$ and 3c shown in Table 3. On the right axis, yield strength values are estimated as $\sigma_{\mathrm{y}}=2.6 \mathrm{HV}$ and the lower limits of $\sigma_{\mathrm{y}}$ or "specified minimum yield strengths” (SMYS) for X80 and X90 grade steels are indicated. 


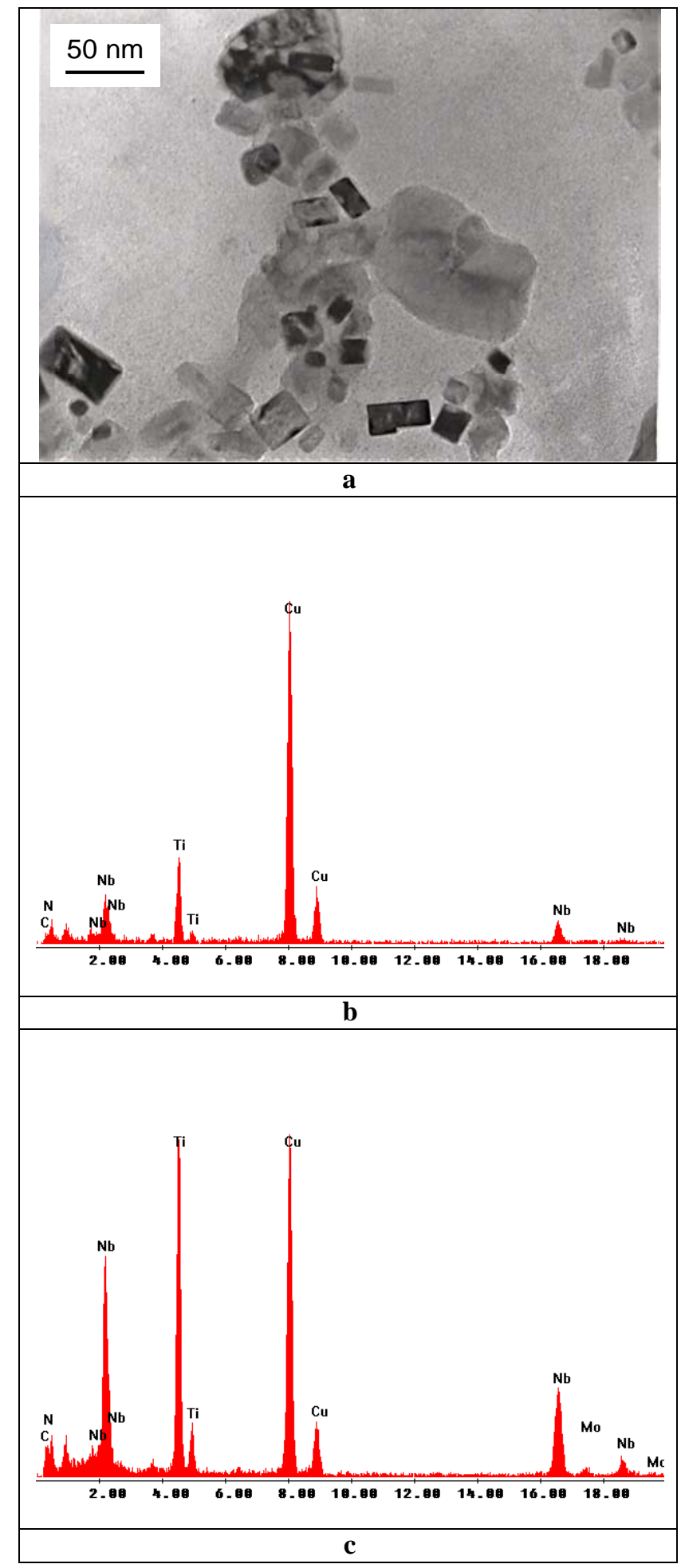

Figure 9. Precipitation state after reheating prior to hot rolling simulation. Quenching temperature $=1150{ }^{\circ} \mathrm{C}$. a) $\mathrm{TEM}$ image of carbon replica showing cuboidal precipitates; b) Energy dispersive X-ray (EDX) analysis spectrum of a precipitate showing the presence of $\mathrm{Ti}$ and $\mathrm{Nb}$; c) EDX analysis spectrum of a precipitate showing the presence of $\mathrm{Ti}$, $\mathrm{Nb}$ and Mo. 


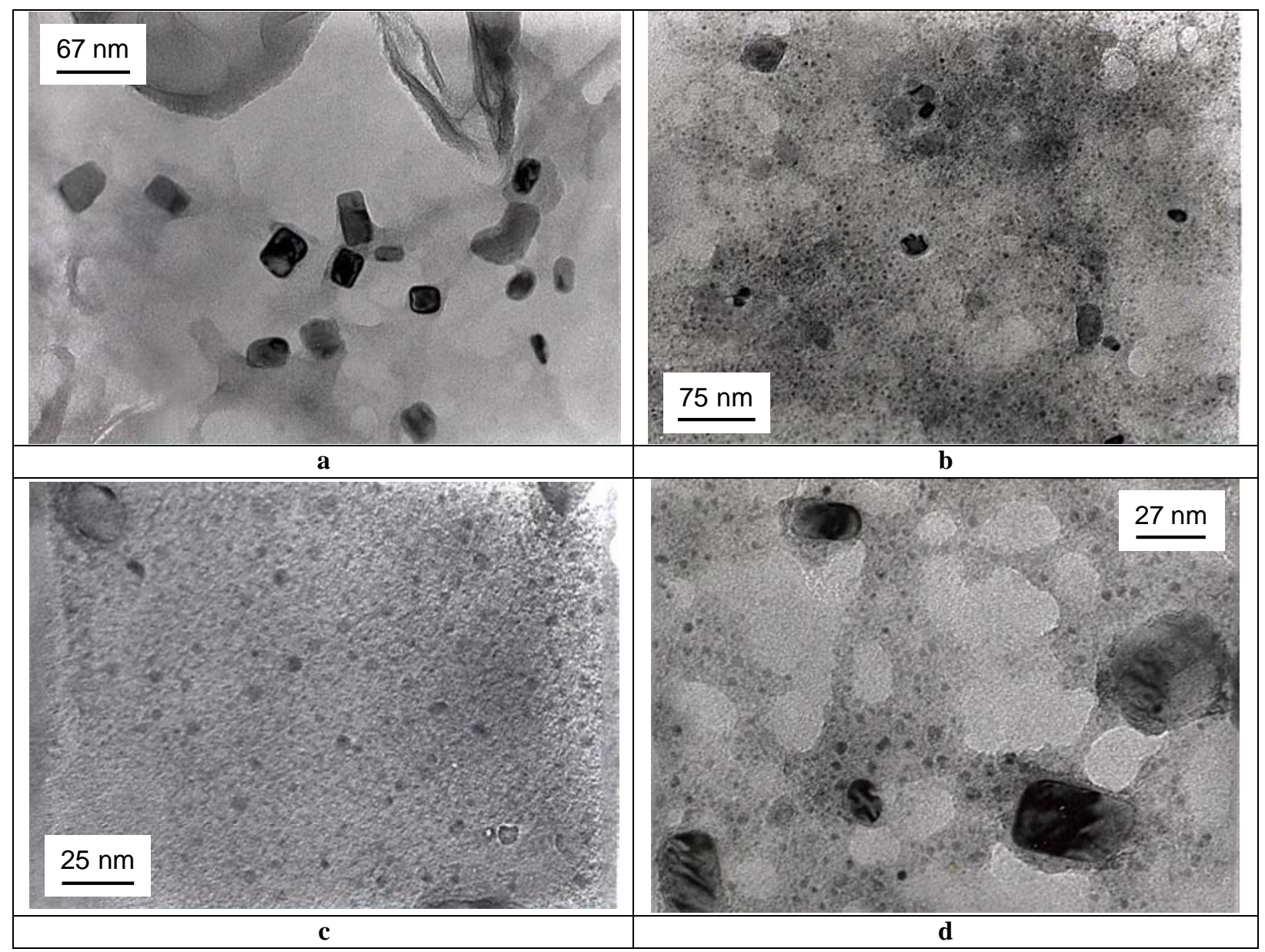

Figure 10. TEM images showing the evolution of precipitation state during hot rolling simulation schedule. "Td" means temperature of the last deformation applied and "Tq" means quenching temperature. a) End of Phase 1 , $\mathrm{Td}=\mathrm{Tq}$ $=1075{ }^{\circ} \mathrm{C}$; b) Coarser and finer precipitates at the beginning of Phase $2, \mathrm{Td}=1075{ }^{\circ} \mathrm{C}, \mathrm{Tq}=870{ }^{\circ} \mathrm{C}$; $\mathbf{c}$ ) Detail showing finer precipitates at the beginning of Phase $2, \mathrm{Td}=1075^{\circ} \mathrm{C}, \mathrm{Tq}=870^{\circ} \mathrm{C}$; d) Coarser and finer precipitates at the end of Phase $2, \mathrm{Td}=\mathrm{Tq}=810^{\circ} \mathrm{C}$. 


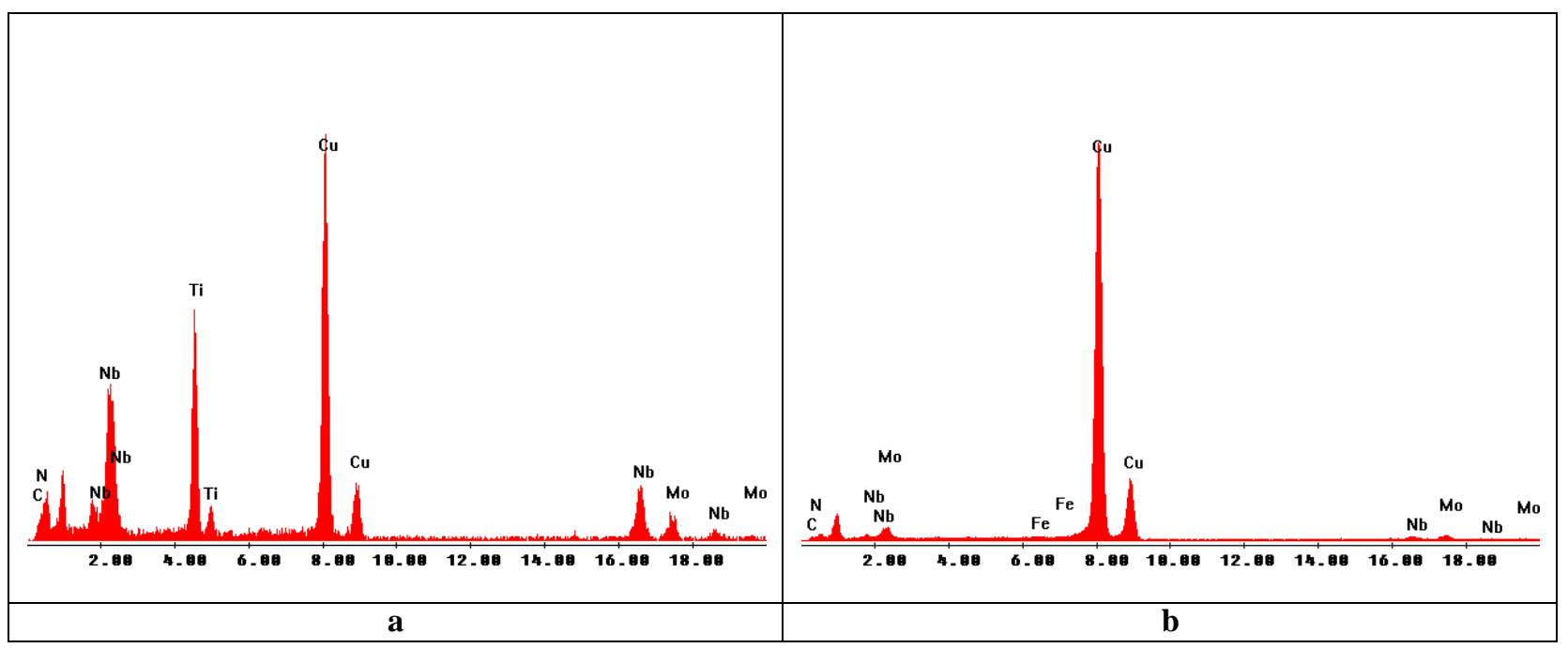

Figure 11. EDX analysis spectra of precipitates found at $810^{\circ} \mathrm{C}$, i.e. the end of Phase 2. a) Coarser particle with Ti, $\mathrm{Nb}$ and Mo; b) Finer and more globular particle with Nb-Mo. 


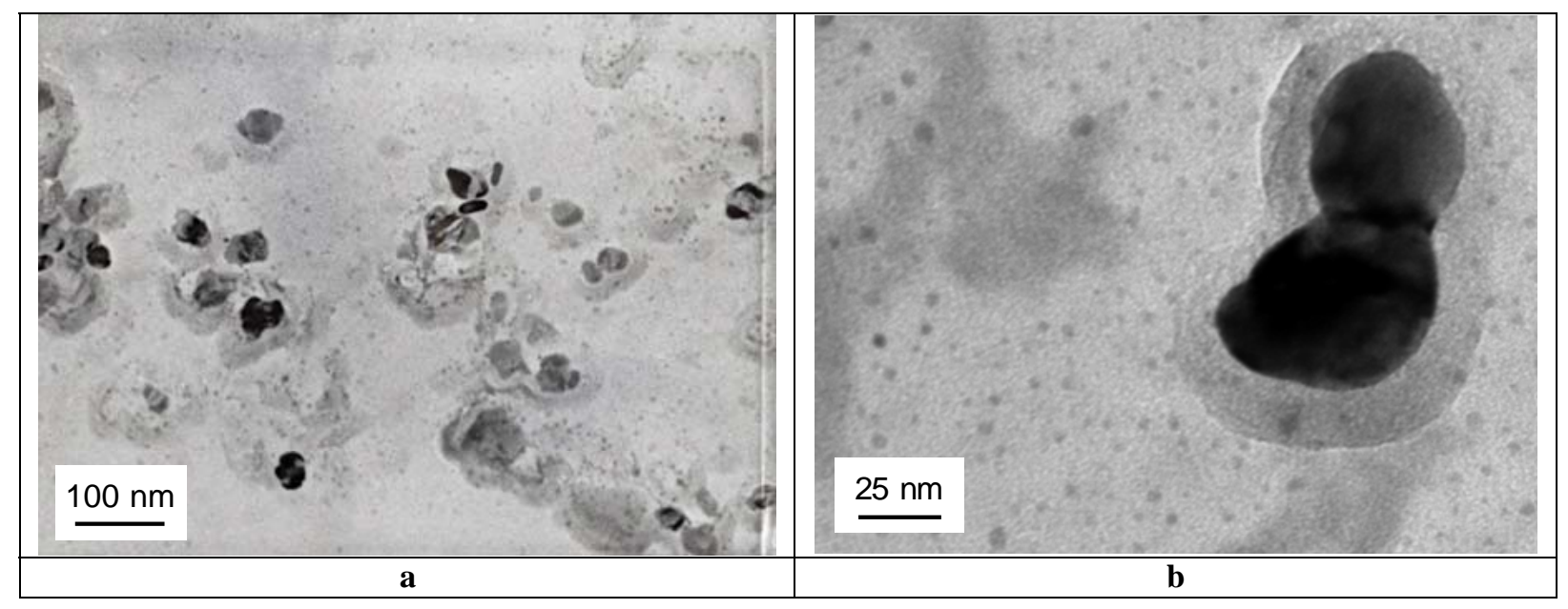

Figure 12. TEM images showing precipitation state obtained at the end of hot rolling simulation. Last deformation temperature $=$ quenching temperature $=750{ }^{\circ} \mathrm{C}$, i.e. at the end of Phase 3 . Two distinct populations of coarse and fine particles can be observed. The coarsest appear sometimes coalesced. a) Phase 3a, lowest $\Delta \sigma$ level; b) Phase 3c, highest $\Delta \sigma$ level. 


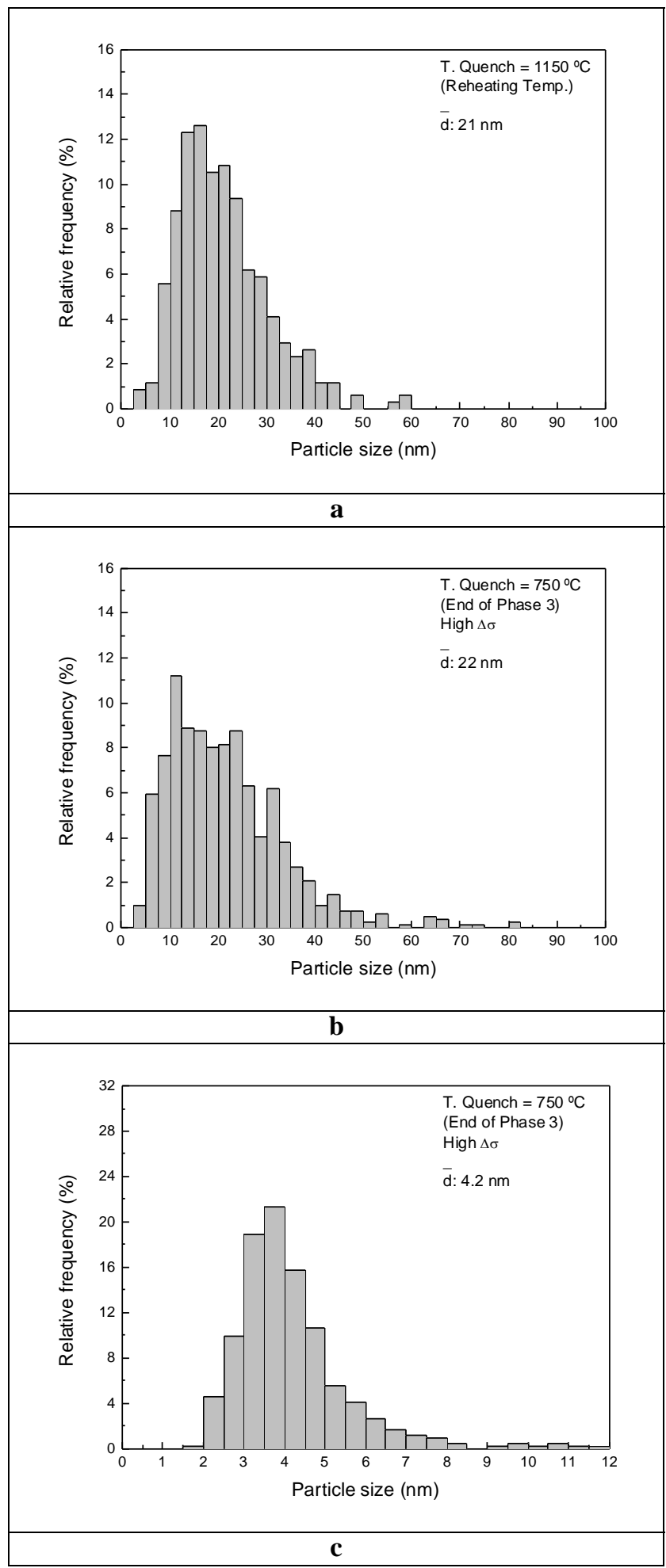

Figure 13. Examples of precipitate size distribution obtained at different stages of hot rolling simulation. a) After reheating at $1150{ }^{\circ} \mathrm{C}$; b) End of hot rolling, $750{ }^{\circ} \mathrm{C}$, High $\Delta \sigma$, Coarser precipitates; c) End of hot rolling, $750{ }^{\circ} \mathrm{C}$, High $\Delta \sigma$, Finer precipitates. 


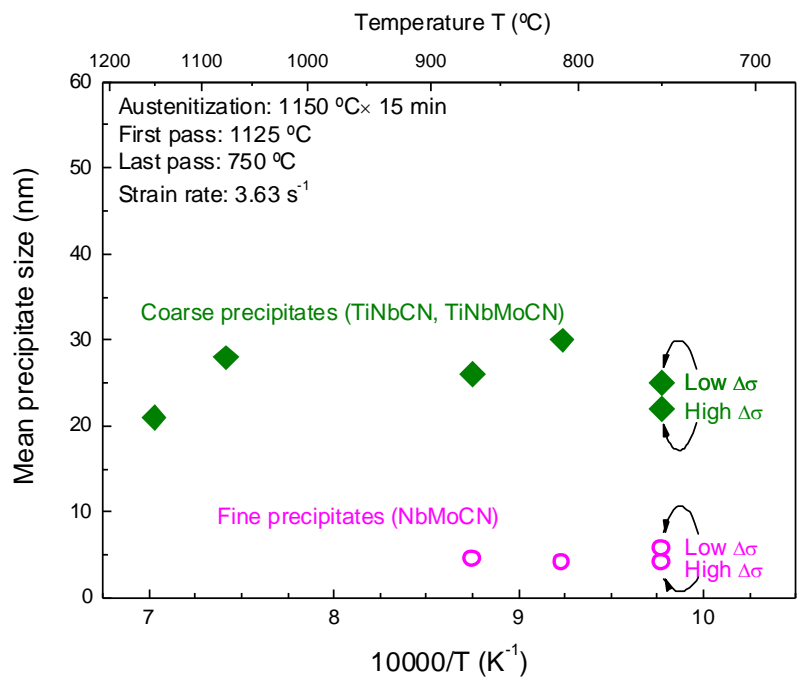

Figure 14. Evolution of mean precipitate size during the hot rolling simulation shown in Figure 2. 